Alternatives to the Maroni Process for Tritium Recovery in Fusion Reactors: Avoiding Volatile Hydrogen Fluoride and High-Temperature High-Speed Rotating Machinery

J. Farmer, B. El-Dasher, T. Bandhauer, A. Rubenchik, S. Reyes, M. Dunne, E. Moses

October 15, 2013 
This document was prepared as an account of work sponsored by an agency of the United States government. Neither the United States government nor Lawrence Livermore National Security, LLC, nor any of their employees makes any warranty, expressed or implied, or assumes any legal liability or responsibility for the accuracy, completeness, or usefulness of any information, apparatus, product, or process disclosed, or represents that its use would not infringe privately owned rights. Reference herein to any specific commercial product, process, or service by trade name, trademark, manufacturer, or otherwise does not necessarily constitute or imply its endorsement, recommendation, or favoring by the United States government or Lawrence Livermore National Security, LLC. The views and opinions of authors expressed herein do not necessarily state or reflect those of the United States government or Lawrence Livermore National Security, LLC, and shall not be used for advertising or product endorsement purposes.

This work performed under the auspices of the U.S. Department of Energy by Lawrence Livermore National Laboratory under Contract DE-AC52-07NA27344. 


\title{
Alternatives to the Maroni Process for Tritium Recovery in Fusion Reactors: Avoiding Volatile Hydrogen Fluoride and High-Temperature High-Speed Rotating Machinery
}

\author{
Joseph Farmer, Bassem El-Dasher, Todd Bandhauer, Alexander Rubenchik, \\ Susana Reyes, Michael Dunne, Edward Moses \\ Lawrence Livermore National Laboratory \\ 7000 East Avenue \\ Livermore, California 94550
}

\begin{abstract}
Fusion reactors now on the drawing table, including LLNL's LIFE reactor, require liquid lithium blankets for cooling and breeding tritium fuel. The tritium fuel must be continuously removed from the blanket so that it can be returned to the reactor for burning, via target manufacturing in the case of LIFE. The baseline process for accomplishing this in the LIFE reactor is the well-known Maroni process which uses high-temperature molten mixed alkali-metal halide salts ( $\mathrm{LiCl}: \mathrm{LiF}: \mathrm{LiBr}$ at $530^{\circ} \mathrm{C}$ ) as an extraction solvent. With the generation of hydrogen isotopes, liquid and gaseous acids such as $\mathrm{HCl}, \mathrm{HF}$ and $\mathrm{HBr}$ (and the deuterium and tritium analogs) form in the salt phase, making these solvents very corrosive, with other problems due to volatility. Following extraction of lithium tritide from the molten lithium, the tritide anion must undergo electrochemical oxidation in a high-temperature electrochemical cell to form tritium gas, which can then be separated by stripping in a stream of inert gas such as xenon or helium. The volatility of hydrogen chloride or the tritium analog $(\mathrm{HCl}$ or $\mathrm{TCl})$, hydrogen fluoride or the tritium analog ( $\mathrm{HF}$ or TF) and hydrogen bromide or the tritium analog $(\mathrm{HBr}$ or $\mathrm{TBr}$ ) complicate this separation. An alternative electrolytic process for the conversion of lithium tritide to tritium gas and metallic lithium is based upon the use of a benign lithium hydroxide $(\mathrm{LiOH})$ or lithium carbonate $\left(\mathrm{Li}_{2} \mathrm{CO}_{3}\right)$, which is an extremely attractive alternative to the very volatile and corrosive lithium halide electrolyte.

The separation of the molten lithium and molten chloride salt phases requires numerous high-temperature $\left(530^{\circ} \mathrm{C}\right)$ high-speed centrifugal separators, with bearings and seals exposed to the highly corrosive fluids. Currently, centrifugal contactors are proposed to contact the liquid lithium in which the tritium is bred with a molten salt extraction solvent. These high-speed centrifugal contactors must operate at high temperature for prolonged periods of time without failure. Such rotating machinery, with a highly corrosive molten salt electrolyte, and a liquid lithium phase threatening liquid metal embrittlement is a source of substantial concern. The invention disclosed here is a non-centrifugal contactor capable of operating without any moving parts.
\end{abstract}




\section{Contents}

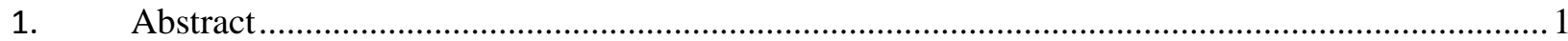

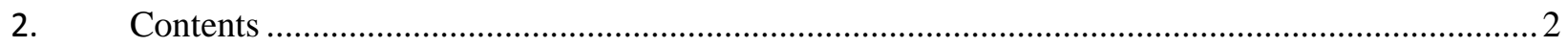

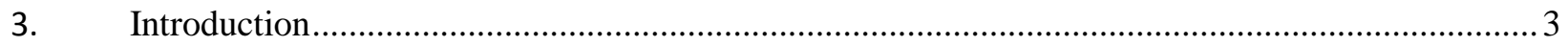

4. Need - Alternative Process for Tritium Recovery …............................................................. 4

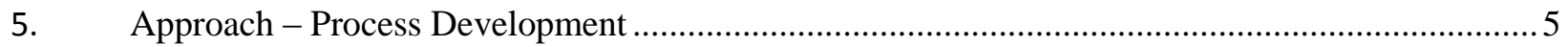

6. Lithium Tritide Extraction from Lithium Breeding Media................................................... 6

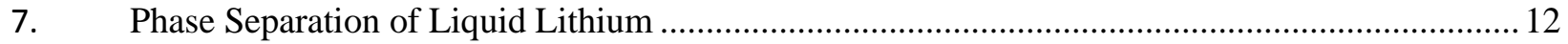

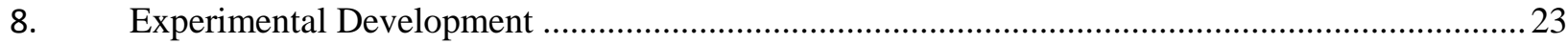

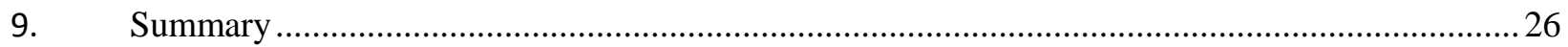

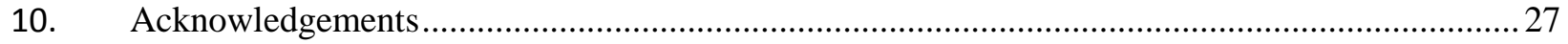

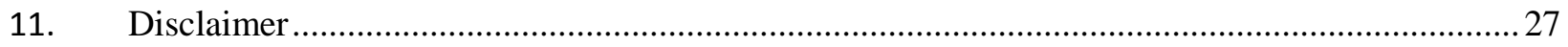

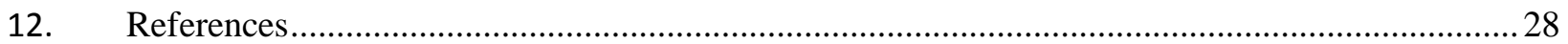




\section{Introduction}

Fusion reactors now on the drawing table, including LLNL's LIFE reactor, require liquid lithium blankets for cooling and breeding tritium fuel.The tritium fuel must be continuously removed from the blanket so that it can be returned to the reactor for burning, via target manufacturing in the case of LIFE. The baseline process for accomplishing this in the LIFE reactor is the well-known Maroni process which uses high-temperature molten mixed alkali-metal halide salts ( $\mathrm{LiCl}: \mathrm{LiF}: \mathrm{LiBr}$ at $530^{\circ} \mathrm{C}$ ) as an extraction solvent. With the generation of hydrogen isotopes, liquid and gaseous acids such as $\mathrm{HCl}, \mathrm{HF}$ and $\mathrm{HBr}$ (and the deuterium and tritium analogs) form in the salt phase, making these solvents very corrosive, with other problems due to volatility. Vapors such as hydrogen fluoride are especially problematic for the solid-state metal hydride beds proposed for on-site tritium storage. Following extraction of lithium tritide from the molten lithium, the tritide anion must undergo electrochemical oxidation in a high-temperature electrochemical cell to form tritium gas, which can then be separated by stripping in a stream of inert gas such as xenon or helium. The volatility of hydrogen chloride or the tritium analog $(\mathrm{HCl}$ or $\mathrm{TCl})$, hydrogen fluoride or the tritium analog ( $\mathrm{HF}$ or $\mathrm{TF}$ ) and hydrogen bromide or the tritium analog $(\mathrm{HBr}$ or $\mathrm{TBr}$ ) complicate this separation. The separation of the molten lithium and molten chloride salt phases requires numerous high-temperature $\left(530^{\circ} \mathrm{C}\right)$ high-speed centrifugal separators, with bearings and seals exposed to the highly corrosive fluids. Currently, centrifugal contactors are proposed to contact the liquid lithium in which the tritium is bred with a molten salt extraction solvent. These high-speed centrifugal contactors must operate at high temperature for prolonged periods of time without failure. Such rotating machinery, with a highly corrosive molten salt electrolyte, and a liquid lithium phase threatening liquid metal embrittlement is a source of substantial concern. The invention disclosed here is a non-centrifugal contactor capable of operating without any moving parts.

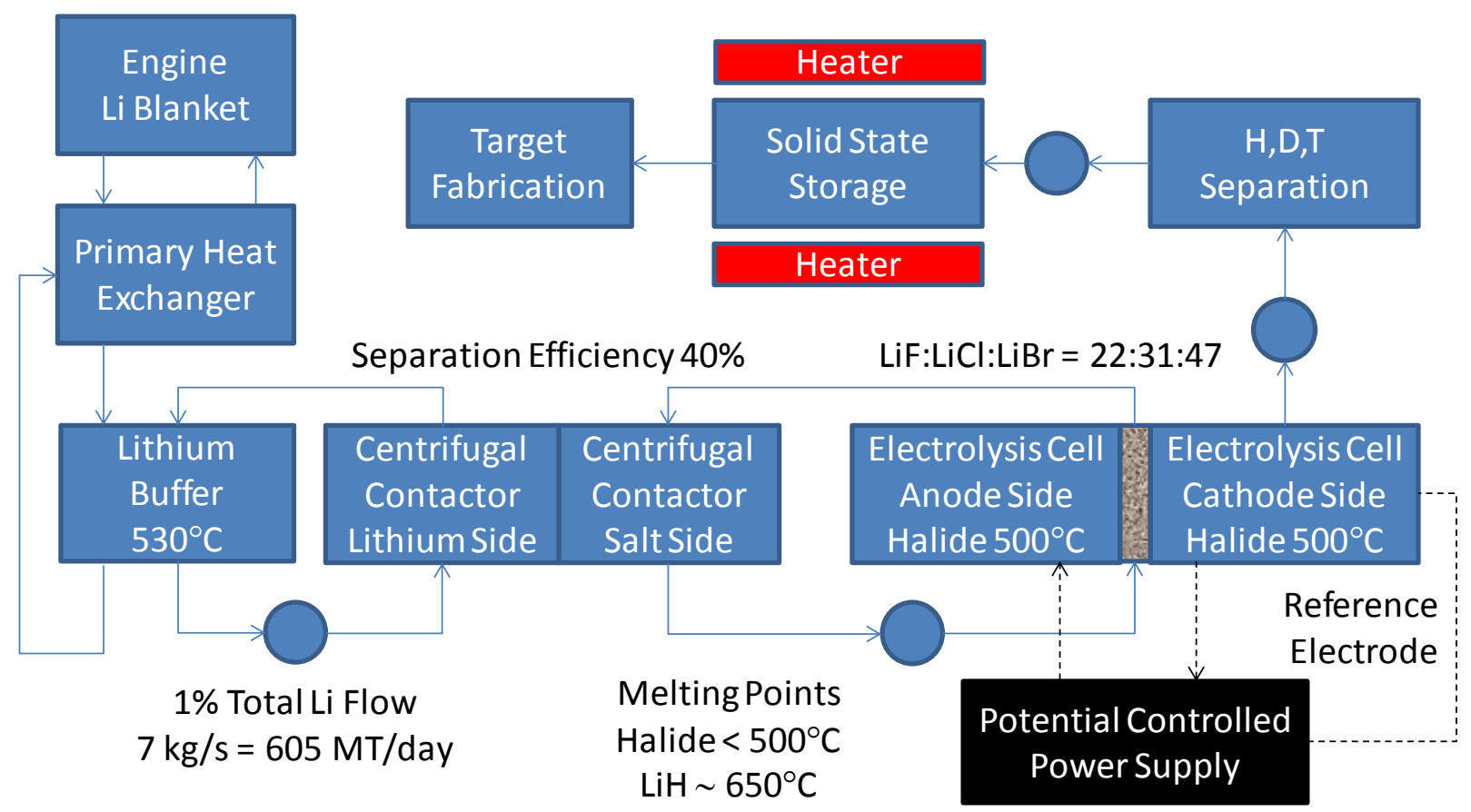

Figure 1 - Tritium recovery from fusion reactor blanket with conventional Maroni process chemistry. 


\section{Need - Alternative Process for Tritium Recovery}

The following specific needs have been identified, and involve the development of an alternative process for recovering tritium from lithium blankets in fusion reactors:

1. Development of a new electrolytic process for the conversion of lithium tritide to tritium gas and metallic lithium based upon the use of benign lithium hydroxide electrolyte, which is an extremely attractive alternative to the very volatile and corrosive lithium halide electrolyte.

2. Testing of lithium hydroxide chemistry in the high temperature electrochemical cell at Lawrence Livermore National Laboratory, which is operated in the well-controlled environment of a glove box.

3. Establishment of phase separation between molten lithium and lithium hydroxide will be demonstrated in a sealed quartz vial.

4. Exploration of pertinent electrochemical reactions in the $\mathrm{LiOH}$ and $\mathrm{Li}_{2} \mathrm{CO}_{3}$ electrolytes at temperature, using cyclic polarization, linear polarization, and electrochemical impedance spectroscopy.

5. Elucidation of electrochemical mechanisms, and the simultaneous determinations of kinetic and mass transport rates, using these techniques.

6. Calibration and validation of electrochemical cell design codes during scale experiments with "seethrough" plastic (Plexiglass ${ }^{\mathrm{TM}}$ ) models, using a surrogate flowing electrolyte, that mimic the flowing molten salt electrolyte, but at ambient temperature.

7. Visualization of pertinent electrochemical reactions and product transport at electrode surfaces in geometrically similar cells, using surrogate electrochemical reactions.

8. Direct comparison of high-speed movies of the observed surrogate electrolytic cell to results predicted with computational fluid dynamic (CFD) simulations that may ultimately serve as reliable design tools for plant scale-up.

9. Development of efficient contactors and separators for molten lithium and molten salts which require no moving parts aside from the pumps required for blanket circulation

10. Detailed design of both optimized electrolytic cells, as well as the new non-centrifugal contactors, for the new alterative tritium-separation process through the application of comprehensive computational fluid dynamics codes.

11. Calibration and validation of the contactor design code during experiments with clear plastic models, using surrogate immiscible fluids to mimic the expected two phase flow at ambient temperature. Solute extraction will be visualized by the transfer of fluorescent dyes from one phase to the other.

12. Direct comparison of high-speed movies of the observed contactor to results predicted CFD simulations that may ultimately serve as reliable design tools for plant scale-up.

13. Engineering designs based upon validated dimensionless correlations of the Sherwood number with the Reynolds and Schmidt numbers. 
Such process development promises numerous benefits, including the possible replacement of problematic lithium halide salts with more benign lithium hydroxide, thereby avoiding corrosion and volatility problems. A new contactor, based upon hydro-cyclones and electromagnetically-pulsed columns, will eliminate the need for high-temperature high-speed centrifugal contactors, with bearings immersed in corrosive fluids at $530^{\circ} \mathrm{C}$. Validated and calibrated computational design codes needed for process scale-up will emerge, as well as new technology for tritium recovery from molten lithium blankets in fusion reactors.

\section{Approach - Process Development}

An alternative electrolytic process for the conversion of lithium tritide to tritium gas and metallic lithium is based upon the use of a benign lithium hydroxide $(\mathrm{LiOH})$ or lithium carbonate $\left(\mathrm{Li}_{2} \mathrm{CO}_{3}\right)$ electrolytes, which is an extremely attractive alternative to the very volatile and corrosive lithium halide electrolyte. In addition to the use of lithium hydroxide, other non-halide salts such as carbonates and nitrates are also being explored, with carbonates preferred. Figure 2 shows the process flow chart for halide-free alternative to Maroni tritium separation process. Molten lithium hydroxide is used to extract lithium tritide from the lithium blanket, or buffer in a centrifugal (or non-centrifugal) contactor. The lithium hydroxide with the dissolved lithium tritide solute then flows through and electrochemical cell, where the lithium tritide is converted to lithium metal, which is deposited on the cathode, and tritium gas, which forms during the anodic oxidation of tritide anion. Alternatives are desperately needed, and will be found during execution of the proposed work scope.

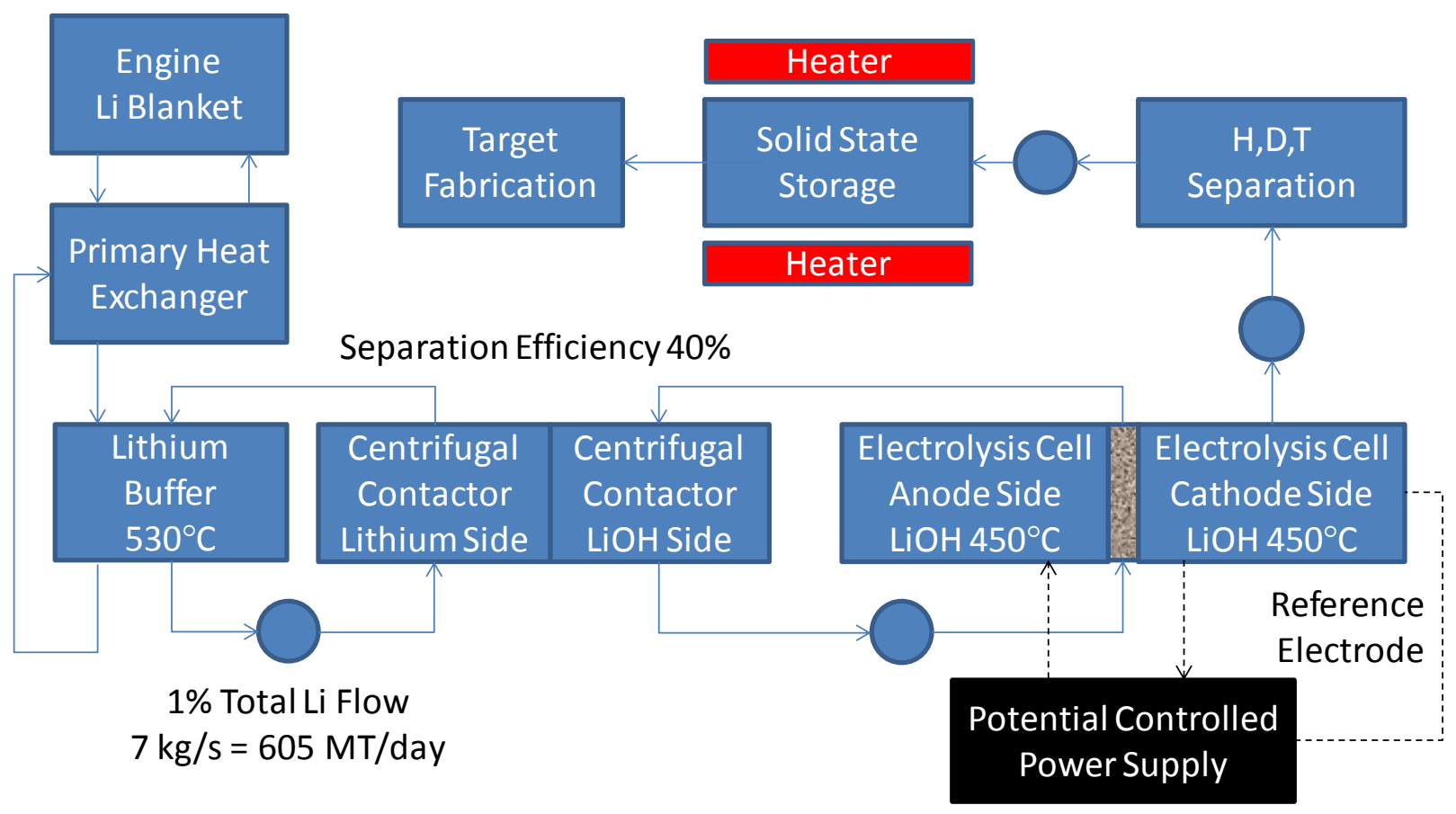

Figure 2 - Process flow chart for halide-free alternative to Maroni tritium separation process. In addition to the use of lithium hydroxide, other non-halide salts such as carbonates and nitrates are also being explored, with carbonates preferred. 


\section{Lithium Tritide Extraction from Lithium Breeding Media}

A. Alternative Non-Halide Salts for Lithium Tritide Extraction: Following extraction of lithium tritide from the molten lithium, the tritide anion must undergo electrochemical oxidation in a hightemperature electrochemical cell to form tritium gas, which can then be separated by stripping in a stream of inert gas such as xenon or helium. As shown in Figure 3, the overall cell reaction involves the electrochemical reduction of lithium cation for form lithium metal at the cell cathode, and the oxidation of tritide anion at the anode to form tritium gas. The open circuit voltage of this cell is expected to be approximately 0.7 volts. These two postulated electrode reactions appear to occur well below the potentials required for anodic dissolution of iron and chromium (corrosive dissolution of materials of construction), and below the potential required for the oxidation of fluoride, chloride or bromide anions, with the formation of the corresponding halogen gases. The volatility of hydrogen chloride or the tritium analog $(\mathrm{HCl}$ or $\mathrm{TCl})$, hydrogen fluoride or the tritium analog (HF or $\mathrm{TF}$ ) and hydrogen bromide or the tritium analog $(\mathrm{HBr}$ or $\mathrm{TBr})$ complicate this separation.

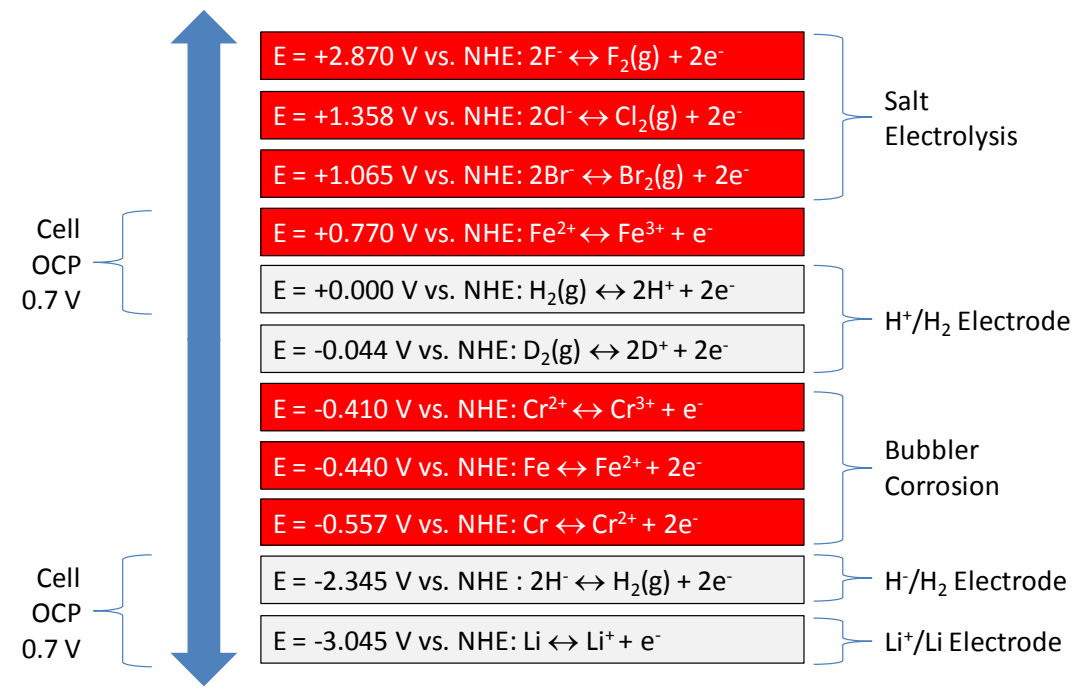

Figure 3 - Electrochemistry involved in the conventional Maroni Process based upon halide salts.

Alternative electrolytic processes for the conversion of lithium tritide to tritium gas and metallic lithium are based upon the use of benign lithium hydroxide electrolyte $(\mathrm{LiOH})$, lithium carbonate $\left(\mathrm{Li}_{2} \mathrm{CO}_{3}\right)$, and perhaps even $\mathrm{LiNO}_{3}$. Figures 4 shows pertinent electrochemistry for halide-free lithium hydroxide alternative to Maroni tritium separation process, showing reactions involved in the conventional process for comparison. Specifically, the mixed molten halide salt used in the conventional process can be converted to bromine, fluorine and chlorine gas as the potential at the anode is increased. In the presence of a concentrated halide salt, the steel anode will also undergo corrosion, with the dissolution of iron and chromium ions, as shown. The oxidation-reduction potentials for conducting these reactions in aqueous solution at standard conditions are known, and are given to provide some insight into the relative potential levels where these reactions occur. Since the electrolyte temperature and concentrations of the various ions are different in the molten salt case, the actual oxidation-reduction potentials will be slightly different. The electrode reactions for the electrolysis cell are expected to occur within the thermochemical limits of the lithium hydroxide electrolyte. Figure 5 shows pertinent electrochemistry for halide-free alternative to Maroni tritium separation process, showing possible electrode reactions only. 


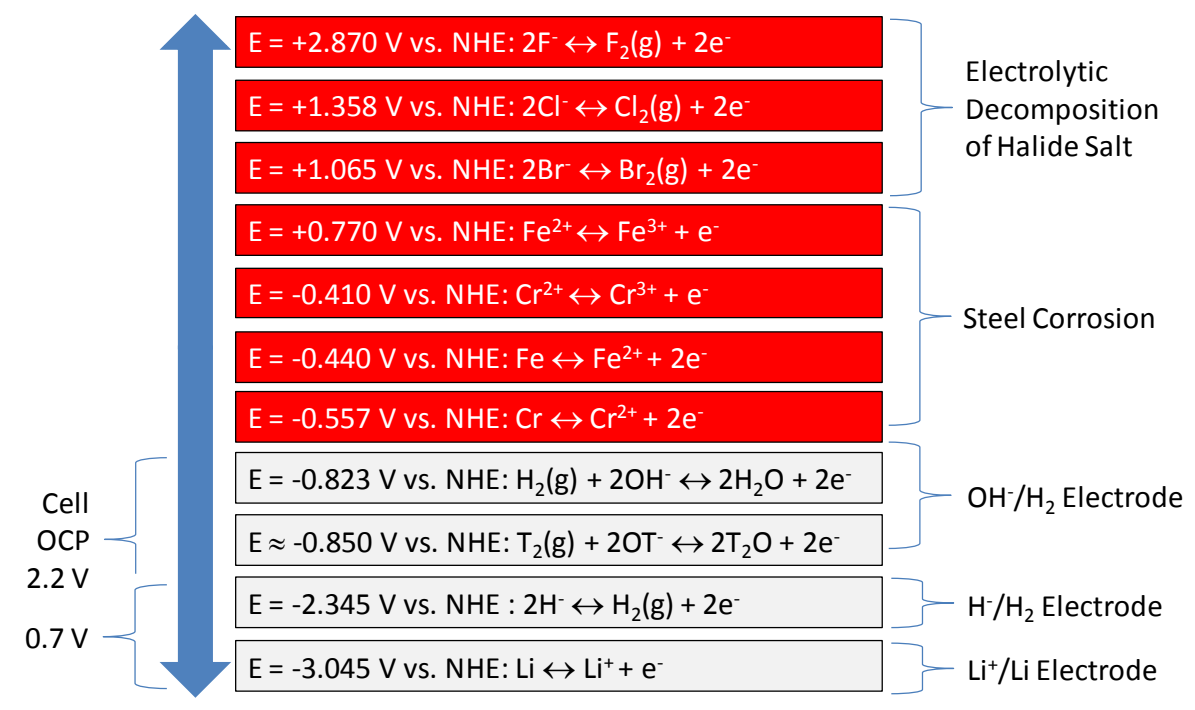

Figure 4 - Pertinent electrochemistry for halide-free alternative to Maroni tritium separation process, showing reactions involved in conventional process for comparison. The electrode reactions for the electrolysis cell are expected to occur within the thermochemical limits of the lithium hydroxide electrolyte.

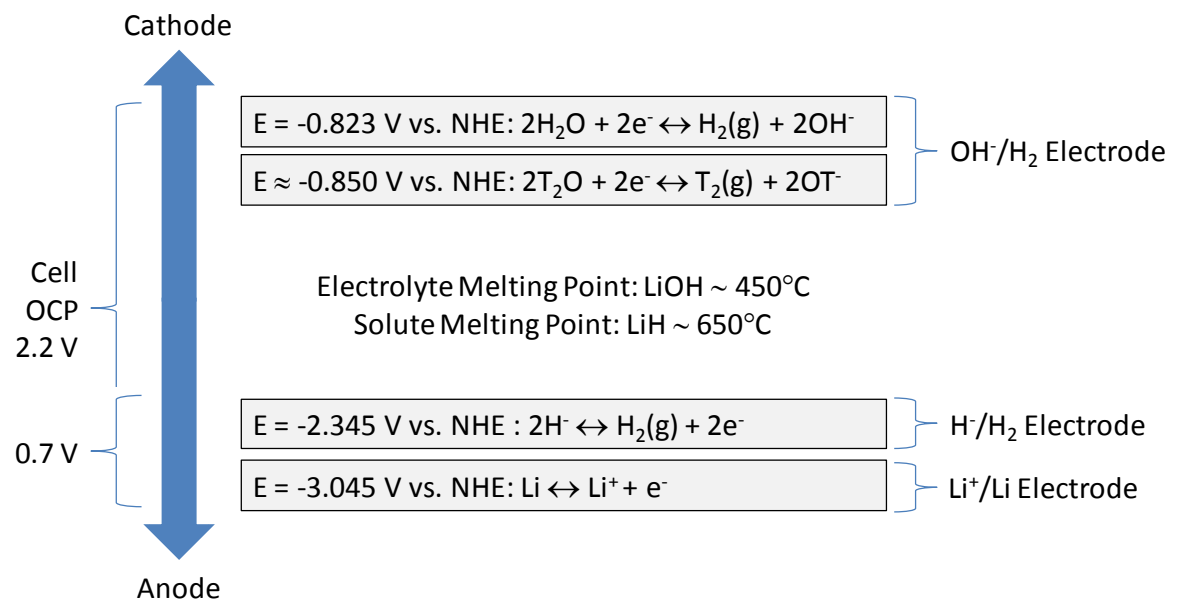

Figure 5 - This figure shows pertinent electrochemistry for halide-free alternative to Maroni tritium separation process, showing possible electrode reactions only.

Lithium hydroxide and lithium carbonate are extremely attractive alternatives to the very volatile and corrosive lithium halide electrolyte. The carbonate may be less prone to tritium retention than the hydroxide, due to the elimination of any isotope exchange reactions involving the hydroxyl anion. The nitrate alternative poses the risk of explosion, and corrosion through the formation of volatile nitric acid. 
B. Optimal Electrolytic Cell Design for Conversion of Lithium Tritide to Tritium Gas: An industrial-scale high-temperature electrolytic cell must be designed to ensure the conversion efficiency required for the conversion of lithium tritide to tritium gas. It is anticipated that the cell will be operating under limiting current conditions, and must therefore be appropriately designed, accounting for mass transport limitations. An undersized or incorrectly sized cell will not meet the design specifications of the LIFE plant. Figure 6 shows schematic representation of the high-temperature electrochemical flow cell for the halide-free alternative to Maroni tritium separation process.

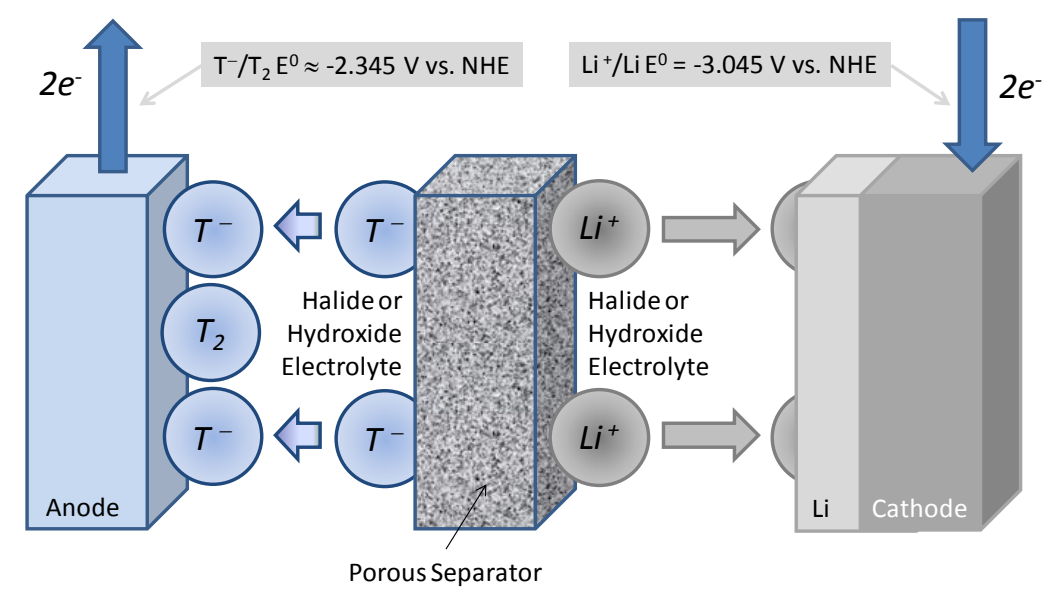

Figure 6 - Conceptual representation of an electrolytic cell required for the conversion of lithium tritide into lithium metal and tritium gas in the conventional Maroni process.

The design of this electrochemical cell required knowledge of the operative mass transport mechanisms in the electrochemical cell. The rate of mass transfer in this electrochemical cell has contributions from diffusion, convection, and electromigration:

$$
\frac{\partial C_{j}}{\partial t}+\mathbf{v} \cdot \nabla C_{i}=z_{j} F \nabla \cdot\left(u_{j} C_{j} \nabla \phi\right)+\nabla \cdot\left(D_{j} \nabla C_{j}\right)+R_{j}
$$

The electromigration term requires knowledge of the potential distribution and simultaneous solution of:

$$
\nabla^{2} \phi=-\frac{F}{\varepsilon} \sum_{j} z_{j} C_{j}
$$

Substantial simplifications are possible for steady state conditions and strong supporting electrolyte.

$$
\begin{aligned}
& \begin{array}{l}
\text { Steady State Strong Supporting Electrolyte } \\
\frac{\partial C_{j}^{J}}{\partial t}+\mathbf{v} \cdot \nabla C_{j}=z_{j} F \nabla \cdot\left(u_{j} C / j \phi\right)+\nabla \cdot\left(D_{j} \nabla C_{j}\right)+R_{j}
\end{array}
\end{aligned}
$$

The design of the required electrochemical cell assumes that the electrochemical reaction for conversion of lithium tritide to lithium metal and tritium gas is diffusion limited. Therefore, the limiting current density at any point along the length of the cell $\left(i_{L}\right)$ being dependent upon the local solute concentration and mass transfer coefficient, which in turn is dependent upon the thickness of the mass transport boundary layer. This boundary layer $(\delta)$, which is shown in Figure 7, is reflected in the Sherwood number $(S h)$, which can be estimated from dimensionless correlations involving the Reynolds and Schmidt numbers $(R e$ and $S c)$. 


$$
\begin{aligned}
& k_{\rho}^{0}=\frac{D_{A B}}{D} \times S h \\
& S h=0.023 S c^{0.33} \operatorname{Re}^{0.80} \\
& \frac{k_{\rho}^{0} D}{D_{A B}}=0.023\left(\frac{\mu}{\rho D_{A B}}\right)^{0.33}\left(\frac{D u_{0} \rho}{\mu}\right)^{0.80}
\end{aligned}
$$

By defining an appropriate control volume, the differential mass balance for lithium tritide solute along the length of the cell can be formulated in terms of a simple ordinary differential equation, whose solution shows that the solute concentration and the corresponding limiting current density decreases with increasing path length $(x)$ in the cell. Integration of the expression for the limiting current density over the entire length of the cell yields the following expression for the total cell current $(I)$, where $n$ is the number of electrons transferred in the reaction, $F$ is Faraday's constant, $F W$ is the formula weight of the solute, $k_{\rho}^{0}$ is the mass transfer coefficient calculated from the flow-rate dependent Sherwood number, $a$ is the width of the anode or cathode compartment in the electrochemical cell, and $G$ is the volumetric flow rate of anolyte or catholyte through the respective compartment.

$I=\frac{n F}{F W} \rho C_{0} G\left[1-\frac{1}{\exp \left[k_{\rho}^{0} \frac{a}{G} x\right]}\right]$

The average current density over the length of the cell $(L)$ calculated by dividing the total current $(I)$ by the area $(A=a \times L)$.

$$
\left\langle i_{L}\right\rangle=\frac{I}{a \times L}=\frac{n F}{F W} \frac{\rho C_{0} G}{a \times L}\left[1-\exp \left[-k_{\rho}^{0} \frac{a}{G} x\right]\right]
$$

If the total current required for conversion of the solute to lithium metal and tritium gas is first calculated with Faraday's law, the average current density, which depends upon the wetted perimeters of the electrode compartment, the lengths of the electrode, the electrolyte flow rate through the electrode compartment, and temperature-dependent properties of the flowing electrolyte, the required electrode area can be calculated as follows:

$$
\text { Area }=\frac{I_{\text {required }}}{\left\langle i_{L}\right\rangle}
$$

Figure 8 shows the results of modeling mass transport in electrochemical flow cell showing need for long path length for conversion of lithium tritide to plated lithium metal and tritium gas. This curve was calculated based upon aforementioned design equations. Figure 9 shows a cell where the required long channel length for conversion of lithium tritide to lithium metal and dissolve tritium gas is achieved in a compact cell with long serpentine flow path. Figure 10 shows a slightly different cell design where large electrode area and enhanced mass transfer are achieved with porous electrodes in a divided cell. 


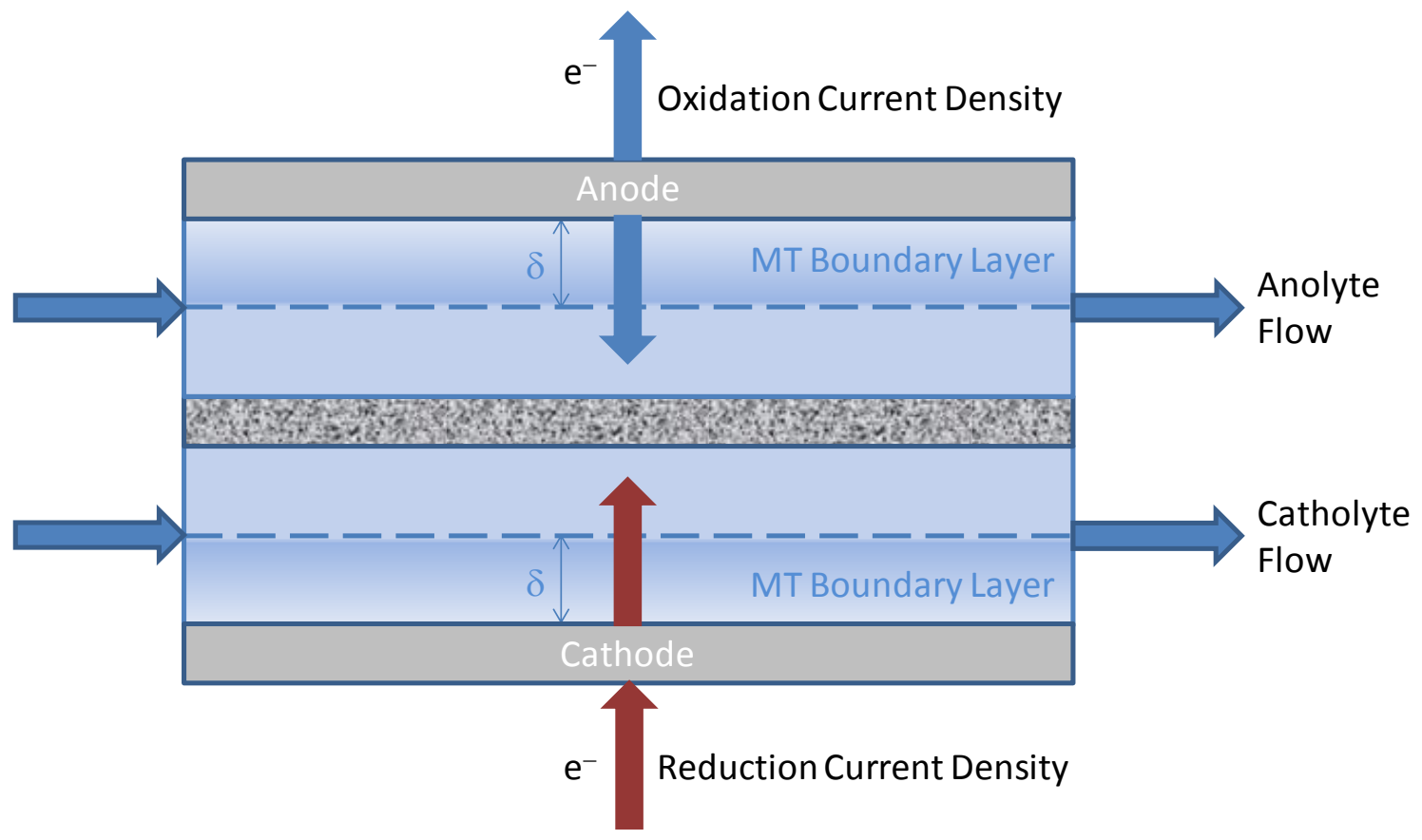

Figure 7 - Design of high-temperature electrochemical flow cell for the halide-free alternative to Maroni tritium separation process.

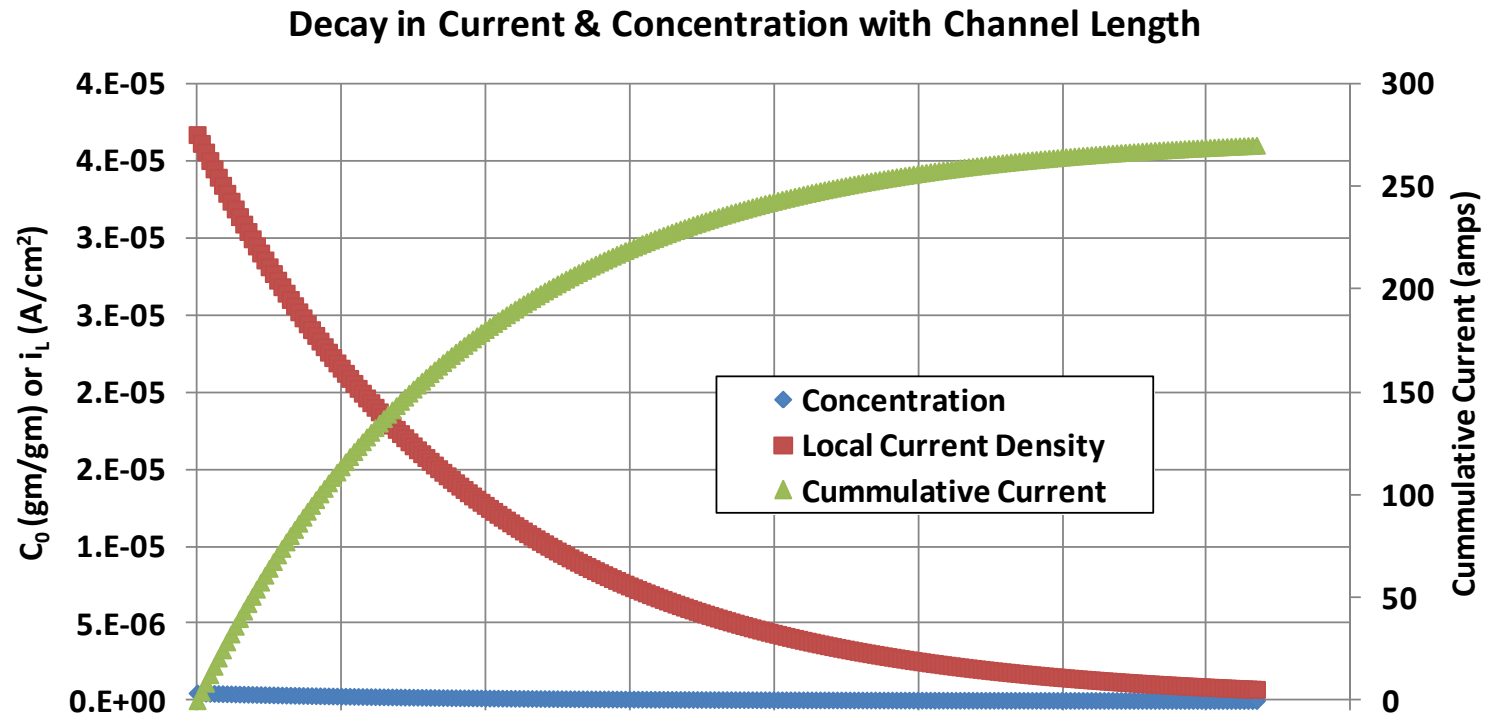

Channel Length $(\mathrm{cm})$

Figure 8 -Results of modeling mass transport in electrochemical flow cell showing need for long path length for conversion of lithium tritide to plated lithium metal and tritium gas. This curve was calculated based upon aforementioned design equations. 


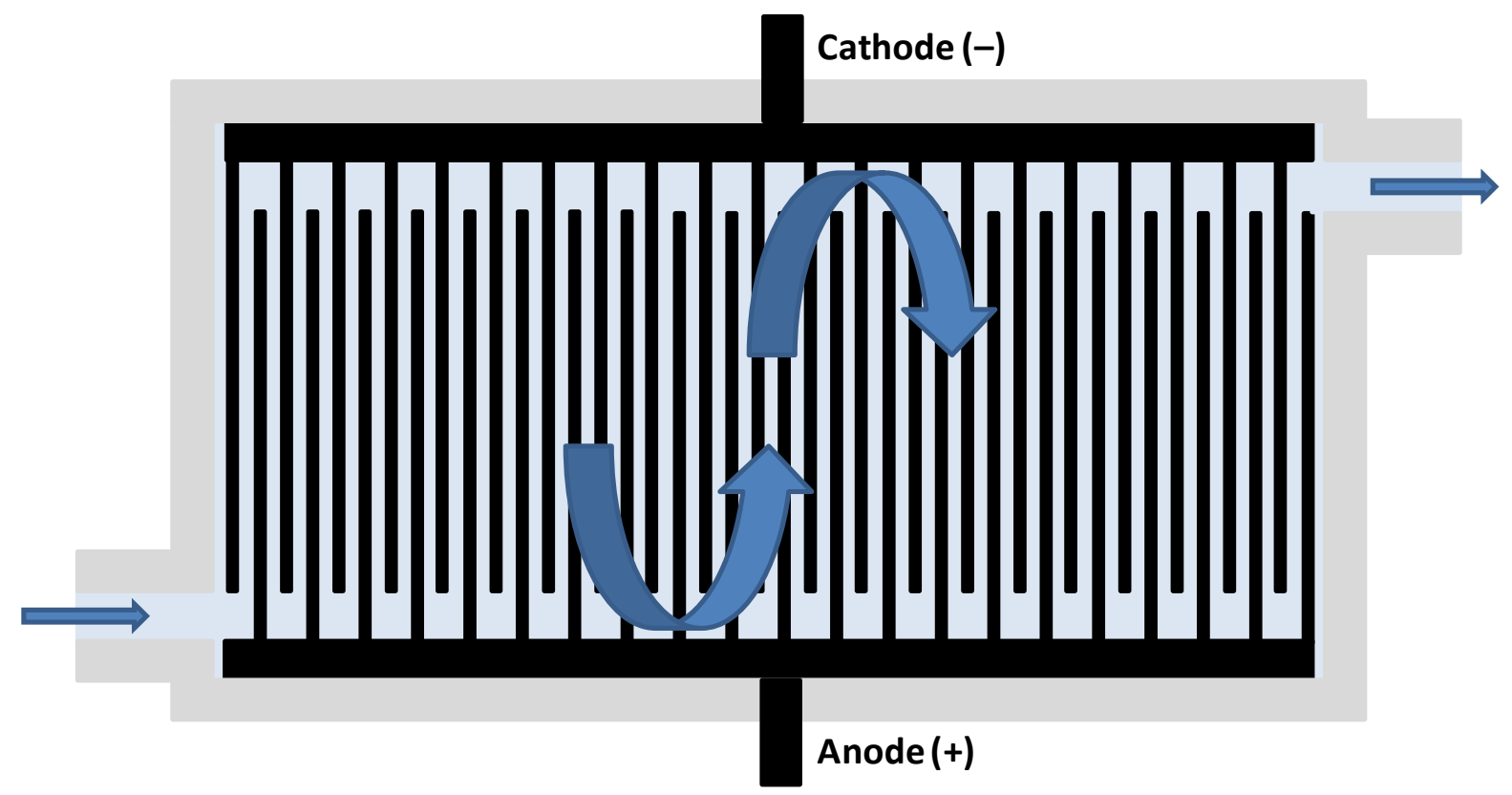

Figure 9 - Achieving long channel length in compact cell with serpentine flow (left).

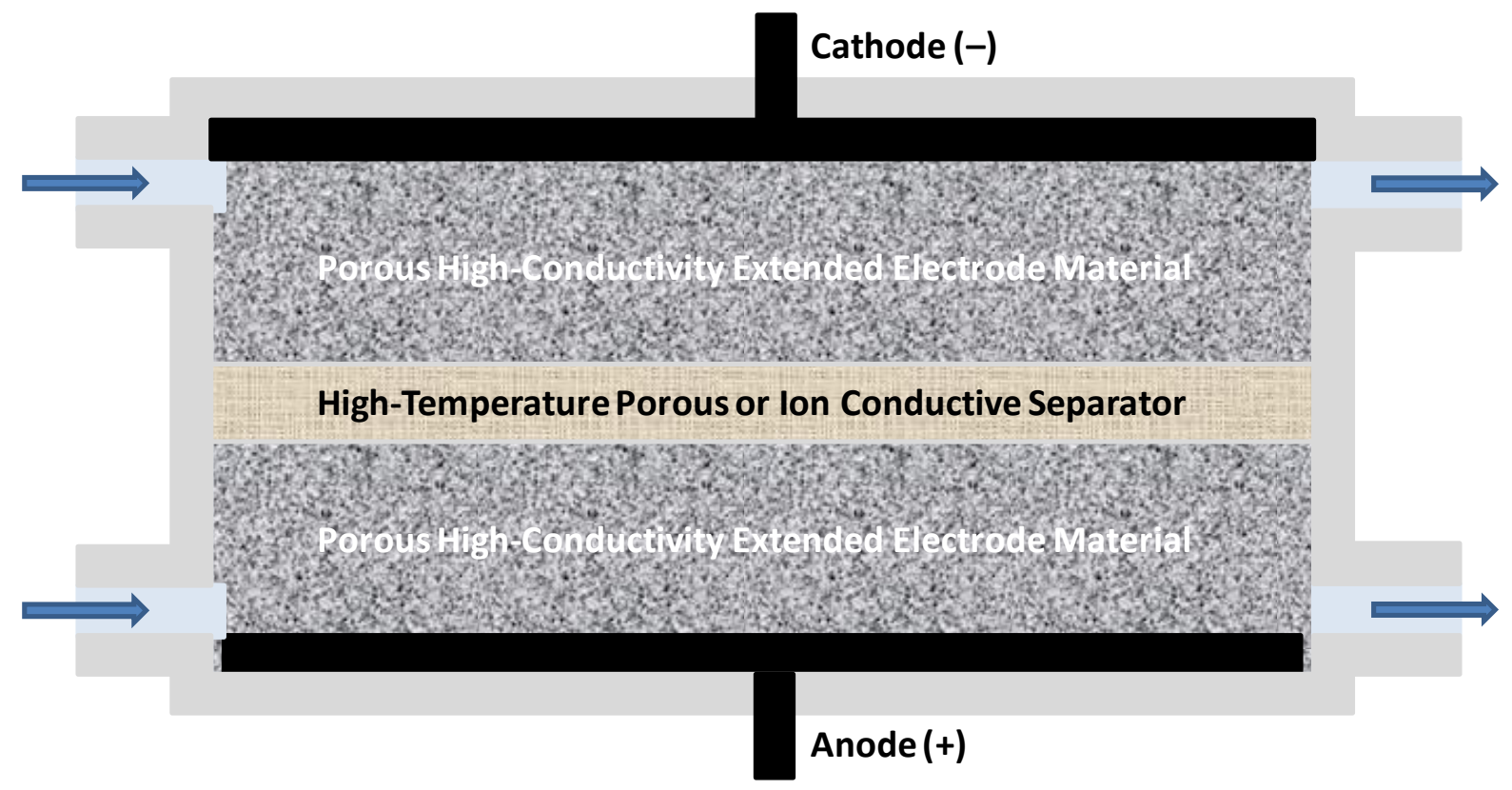

Figure 11 - Achieving large area and enhanced mass transfer with porous electrode (right). 


\section{Phase Separation of Liquid Lithium}

A. Alternatives to High-Temperature High-Speed Centrifugal Contactors: Currently, centrifugal contactors are used to contact the liquid lithium in which the tritium is bred with a molten salt extraction solvent. These high-speed centrifugal contactors must operate at high temperature for prolonged periods of time without failure. Such rotating machinery, with a highly corrosive molten salt electrolyte, and a liquid lithium phase threatening liquid metal embrittlement is a source of substantial concern. In general, and as illustrated in Figure 10, a contactor must perform the following generalized functions: (1) maximize surface area between phases; (2) create conditions for high $\mathrm{K}_{\mathrm{M}}{ }^{*}$ by manipulating both phases; enable sufficiently long Residence Time; and (4) consolidate and separate the flowing liquid lithium and molten salt phases.

The approach proposed here will enable the molten-salt extraction of tritium from flowing lithium, while achieving reliability substantially better than that possible with centrifugal contactors. This approach will avoid the use of high-temperature rotating machinery, and associated problematic seals and bearings by relying on simple flow systems. Specifically, the following will be accomplished:

1. Maximizing interfacial surface area between the two flowing phases by utilizing:

a. Distributer plates with holes, suspended in the flow

b. Ultrasonic emulsification

c. Bi-stable flapping hydrofoil surfaces in the flowing stream.

2. Providing adequate residence time for inter-phase mass transfer by

a. Designing the flow system with sufficient volume

3. Use of turbulence to increase their inter-phase mass transfer coefficient by

a. Increasing the linear velocity and mass transfer for droplets with pulsed flow

b. Increasing the linear velocity and mass transfer for droplets with electromagnetic modulation

c. Incorporating turbulence promoters in the flow channel

d. Achieving high levels of agitation with ultrasonic

4. Consolidating and separating the liquid lithium and molten salt phases by utilizing

a. Flow pulsations causing collision and contact between droplets of variable size and drag force

b. Cyclonic action during flow

c. Ultrasonic agglomeration to decrease the surface to volume ratio of the distributed phase 


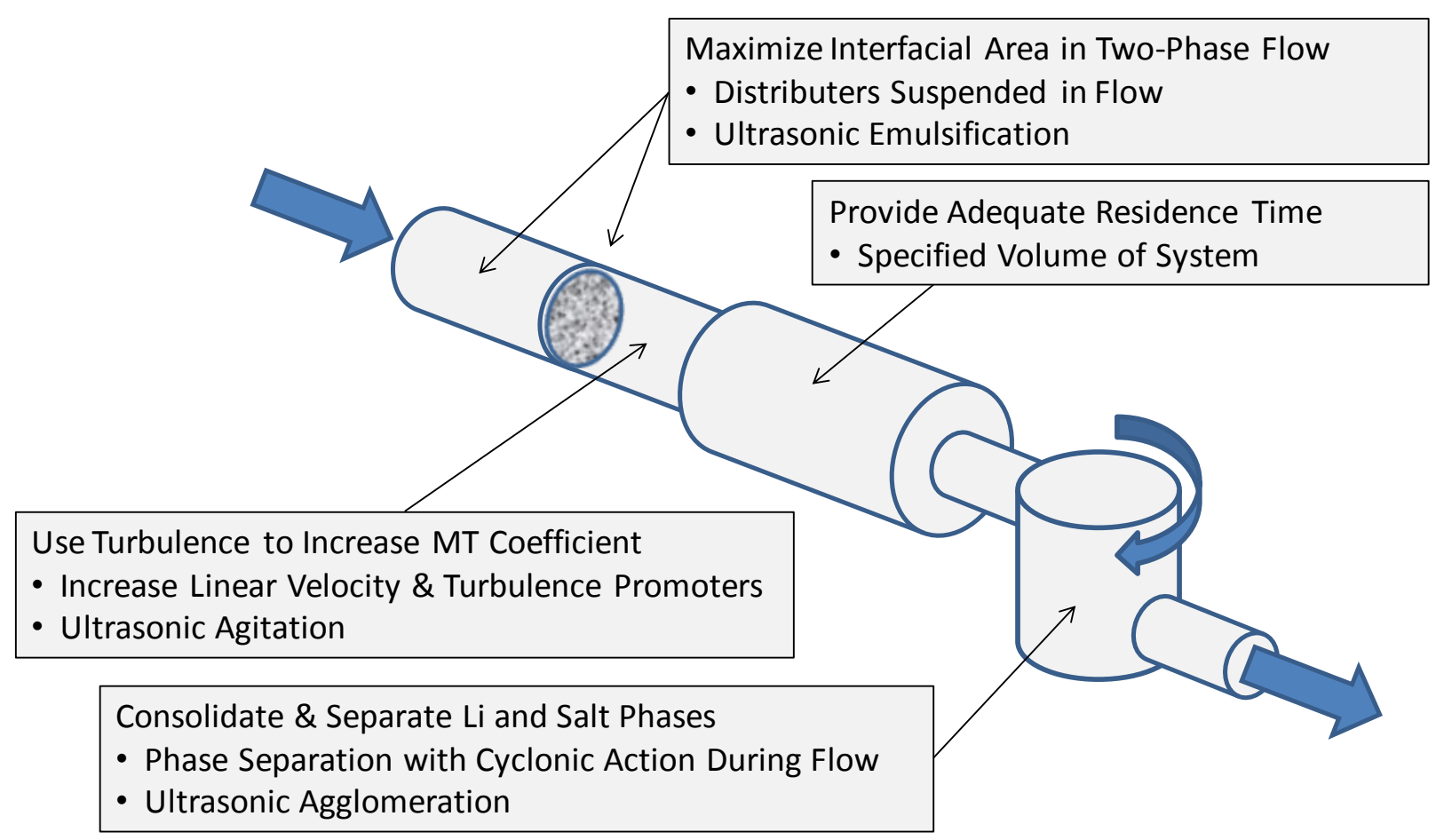

Figure 10 - Functionality required for the development of an alternatives to high-temperature centrifugal contactors, thereby avoiding the problems associated with high-temperature rotating machinery.

A sound scientific basis will be employed for predicting contactor efficiency, and will be used as the basis of engineering design codes that will be developed as a result of the proposed work. The extraction efficiency depends upon the distribution coefficient $\left(D_{V}\right)$, the overall interphase mass transfer coefficient between the lithium and salt phases $\left(K_{M}{ }^{*}\right)$, the interfacial surface area, and the lithium flow rate $(F)$.

$$
\eta=\frac{1-\exp \left(-\frac{\left(1+D_{V}\right) K_{M}^{*} A}{D_{V} F}\right)}{1+D_{V} \exp \left(-\frac{\left(1+D_{V}\right) K_{M}^{*} A}{D_{V} F}\right)}
$$

This specific equation is presented in the published literature [H. Moriyama, Y. Asaoka, Y. Ito, Kinetics of Tritium Recovery from Liquid Lithium by Molten Salt Extraction, Fusion Technology, 19 (1991) 1046-1050]. The overall interphase mass transfer coefficient, represented as a mass transfer resistance (inverse), is then calculated from the two series mass transfer resistances, one for the lithium phase, and the other for the salt phase.

$$
\frac{1}{K_{M}^{*}}=\frac{1}{k_{\rho(L i)}^{0}}+\frac{1}{k_{\rho(s a l t)}^{0}}
$$

The fraction of the lithium blanket that must be processed is then:

$$
X=\frac{R_{b}}{I_{S S}} \frac{\varepsilon D_{V} \eta+1}{\varepsilon D_{V} \eta}
$$


The corresponding lithium flow rate through the process is then:

$$
F=\frac{R_{b}}{C_{S S} \rho_{L i}} \frac{\varepsilon D_{V} \eta+1}{\varepsilon D_{V} \eta}
$$

The dependence of lithium tritide (LiT) solute concentration in the two contacted phases on residence time is shown in Figure 13, showing the solute concentration reaching equilibrium at very long residence time (large contactor volume). Figure 14 shows the relationship between the fractional extraction efficiency and the interphase contact area, with the efficiency increasing dramatically with more surface area. Increased surface area is achieved with smaller droplet sizes, which can be controlled to some extent in the invention described here by the size of holes or pores in the distributer plate. Figure 15 shows the dependence of the fractional extraction efficiency on lithium flow rate, showing improved efficiency at lower flow rates, due to the correspondingly longer residence time.

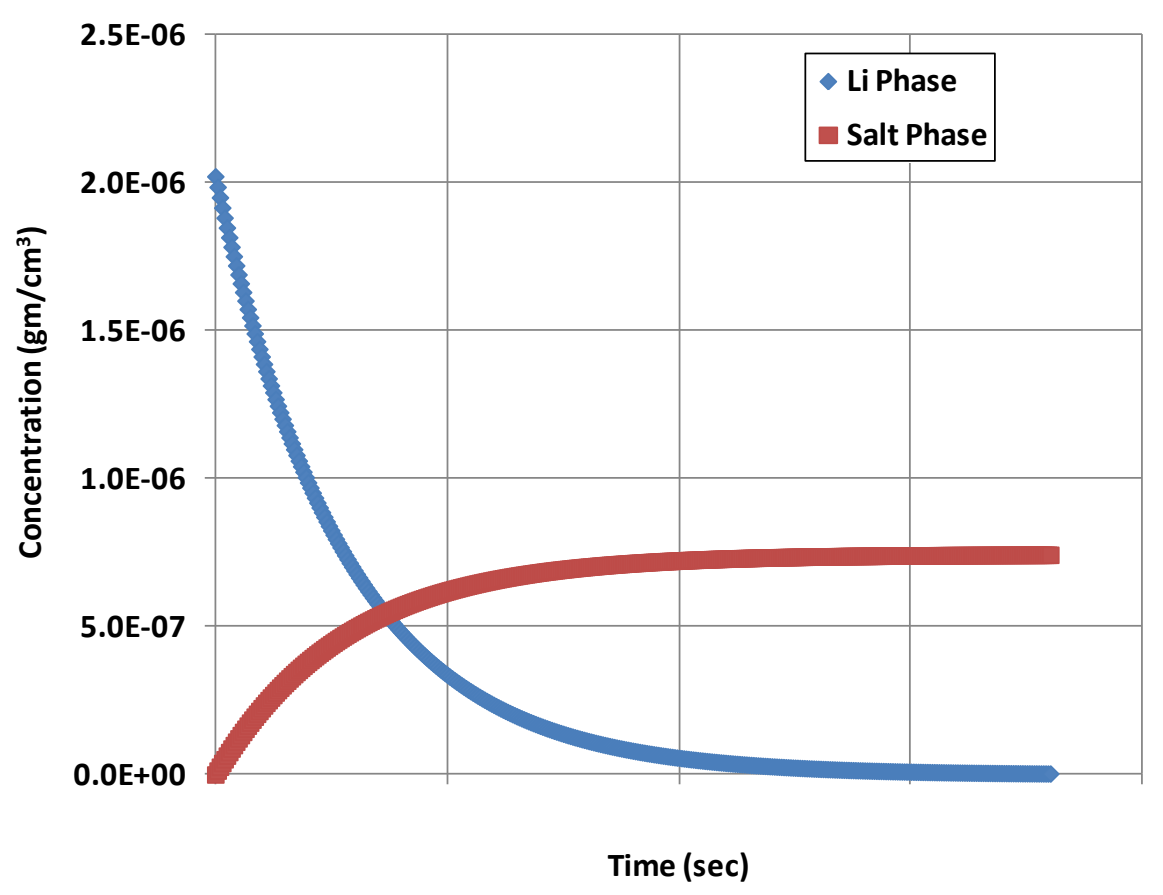

Figure 11 - Lithium tritide concentration in Li and salt phases as a function of contactor residence time. 


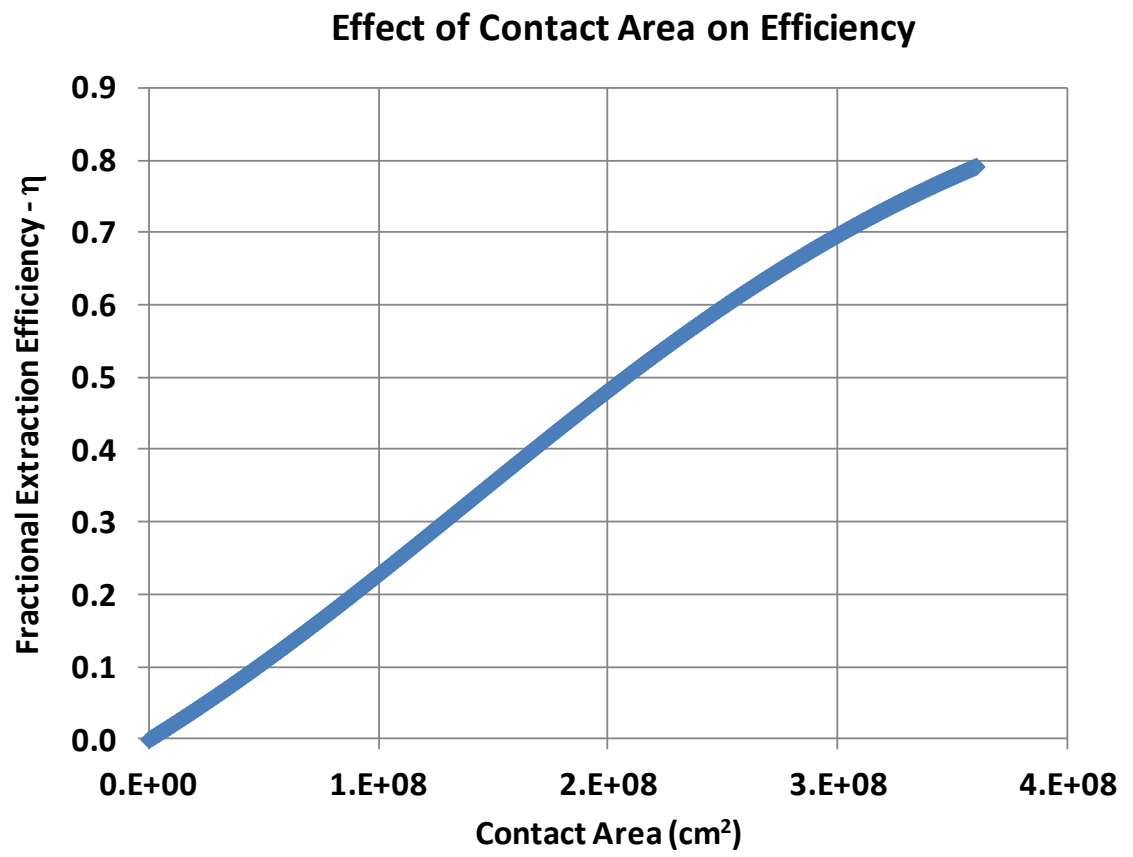

Figure 12 - Relationship between the fractional extraction efficiency and the interphase contact area.

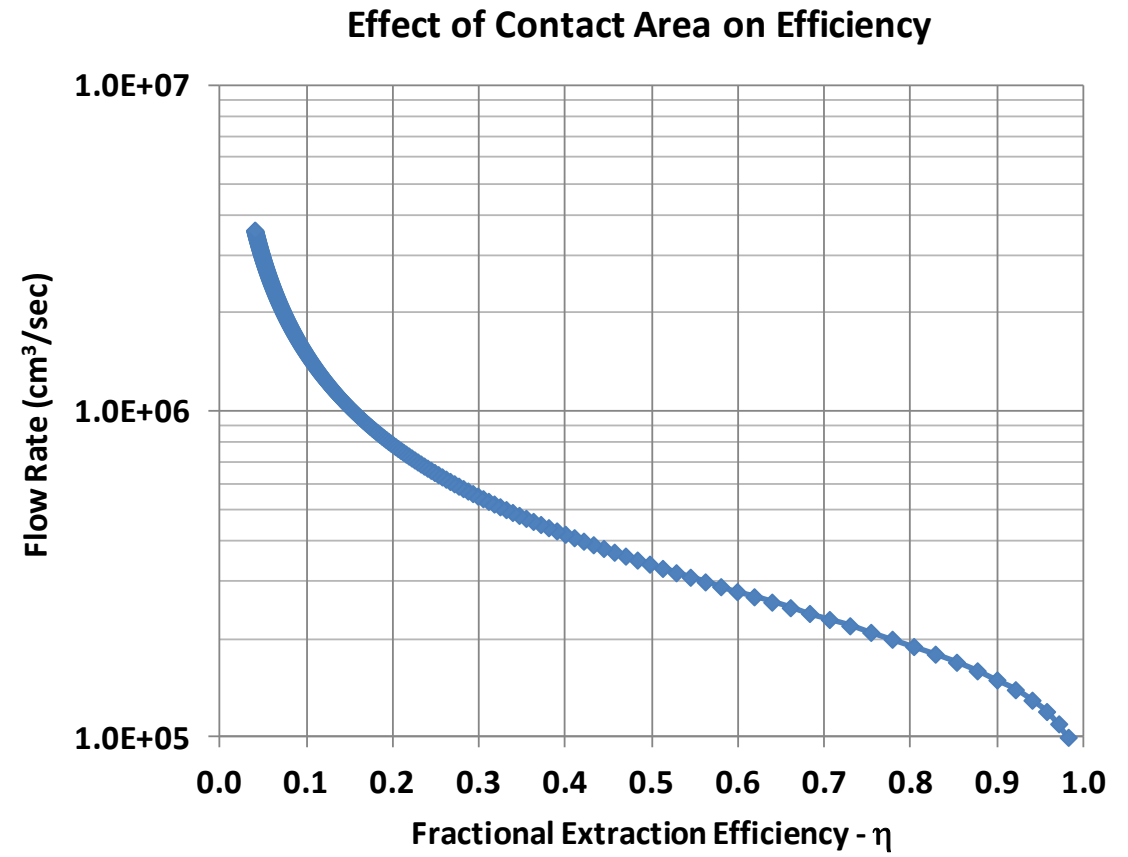

Figure 13 - Dependence of the fractional extraction efficiency on lithium flow rate, showing improved efficiency at lower flow rates, due to the correspondingly longer residence time. 
B. Contactors Driven by Gravity and Centrifugal Force: On option for avoiding problematic hightemperature high-speed centrifugal contactors are contactors driven by the difference in density between the two phases being contacted, and which rely on either gravity or centrifugal force through applied through the cyclonic action of the flow. The mass transfer coefficient governing the interphase transport of lithium tritide from the liquid lithium to the molten salt phase is flow rate dependent, and determined from the velocity of one phase relative to the other. High velocities are beneficial, in that they enhance the mass transfer coefficient.

First, consider the following embodiment of the invention, shown in Figure 14. The volume following the distributer plate can be configured as a vertical column, thereby enabling the substantial density difference between the liquid lithium and molten salt extraction salt to be exploited to induce flow in the distributed phase. Phases can be consolidated at the extreme ends of the vertical column. In a variant of the vertical column, two distributor plates can be used at extreme ends of the column, one for creating a distributed discontinuous alpha phase at the bottom of the column, and another for creating a distributed discontinuous beta phase at the top of the column. Consolidation of the two phases at opposite ends of the column, thereby enabling the simultaneous removal of the two separated phases from opposite ends of the column.

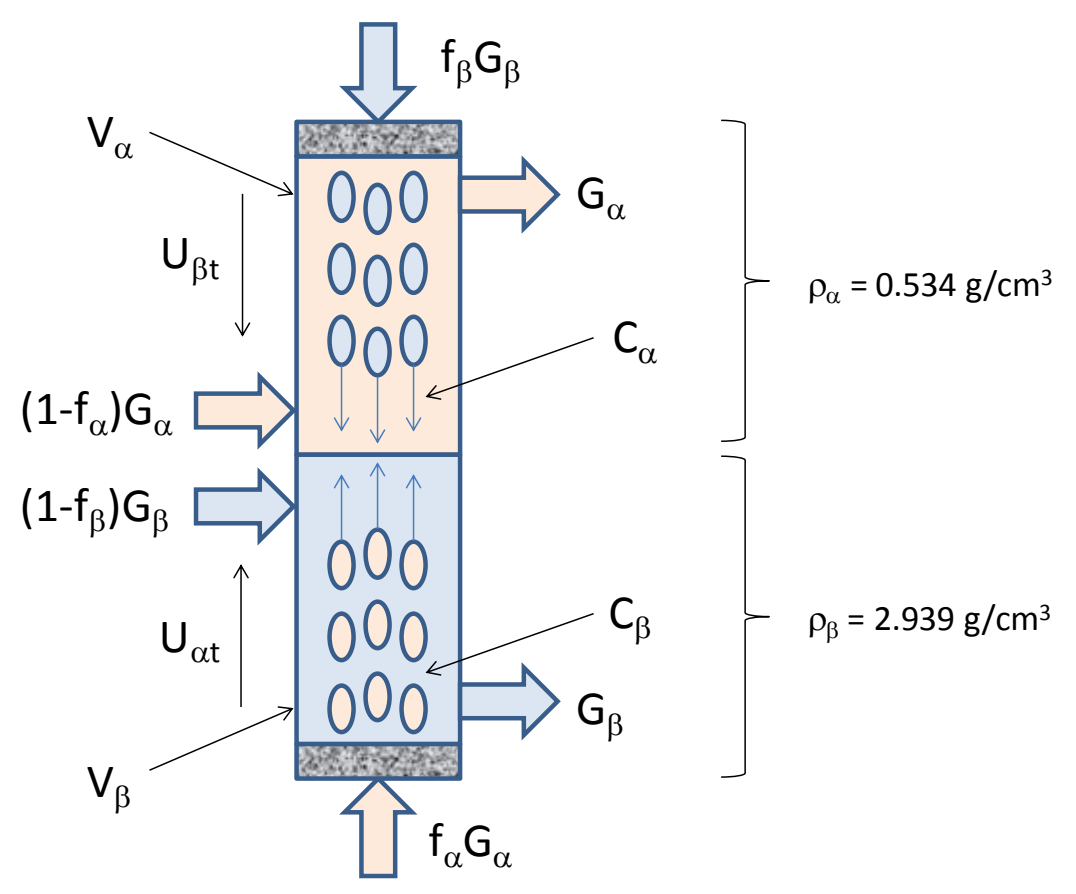

Figure 14 - A vertical column with two distributor plates on opposite ends of the column is one example of a simple gravity-driven system with no moving parts, other than the pumps required for movement of the fluid through the loop. 
Harriott's Method treats particles suspended in agitated vessels as spheres moving at terminal velocity, an application of Stoke's Law:

$U_{T S}=\frac{d_{p}\left|\rho_{d}-\rho_{c}\right| g}{18 \mu_{c}}$

In this expression, $d_{p}$ is the diameter of the droplets comprising the dispersed phase, $\rho_{d}$ is the density of those droplets, $\rho_{c}$ is the density of the continuous phase in which the droplets are immersed, $g$ is the acceleration of gravity, and $\mathrm{mc}$ is the viscosity of the continuous phase. The following equivalences are recognized for the sake of calculating the mass transfer coefficient for the droplets.

$u_{0}=U_{T S}$

$D=d_{p}$

In the case of a dispersed phase consisting of light droplets of lithium rising through a heavier salt phase, or alternatively, heavy droplets of salt falling through a lighter lithium phase, the individual mass transfer coefficients can be calculated from the Sherwood number for a sphere moving at terminal velocity.

$k_{\rho}^{0}=\frac{D_{A B}}{D} \times S h$

The diffusivity of solute A in phase B is $D_{A B}$, the sphere diameter is $D$, and the Sherwood number is $S h$. The Sherwood number is a function of the Schmidt and Reynolds numbers for an assumed spherical drop moving at terminal velocity. Modified Frössling equation for spheres and cylinders:

$S h=2+0.6 S c^{1 / 3} \operatorname{Re}^{1 / 2}$

Substitution of the expression for the Sherwood number into the equation defining the mass transfer coefficient yields the following:

$$
\frac{k_{\rho}^{0} D}{D_{A B}}=2+0.6\left(\frac{\mu}{\rho D_{A B}}\right)^{1 / 3}\left(\frac{D u_{0} \rho}{\mu}\right)^{1 / 2}
$$

The performance of a simple gravity-driven vertical extraction column of the type shown in Figure 14 is summarized in the following performance curves, derived based upon the assumed geometry. Figure 15 shows the calculated tritium concentration in lithium phase for this simple geometry, Figure 16 shows the calculated tritium concentration in molten salt phase, Figures 17 and 18 show the corresponding total or combined size of the bank of columns, and Figure 19 show the size of a bank of such vertical extraction columns with no attempt at optimization $(10 \mathrm{~m} \times 15 \mathrm{~m} \times 15 \mathrm{~m})$. As a baseline, the performance possible with a simple non-centrifugal gravity-driven system with droplets created by 10 , 50 and 100 micron distributor plates has been investigated. Assuming conservative values of diffusivity, such a system is found to be relatively large during preliminary analysis. 
Tritium Concentration in Lithium vs. Contactor First-Stage Volume (Residence Time)

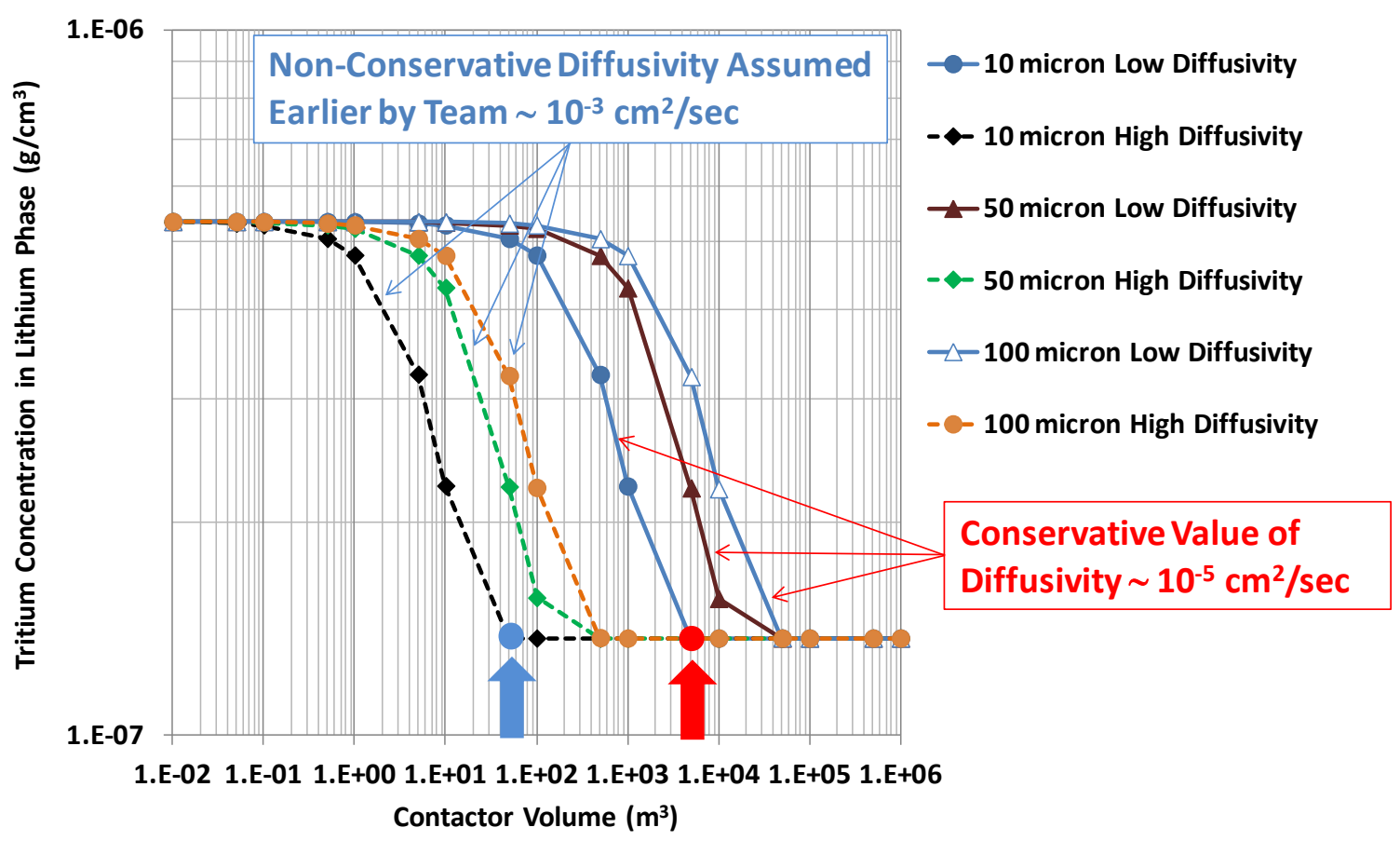

Figure 15 - This figure shows the calculated tritium concentration in liquid lithium phase for vertical extraction column of the type shown in Figure 14.

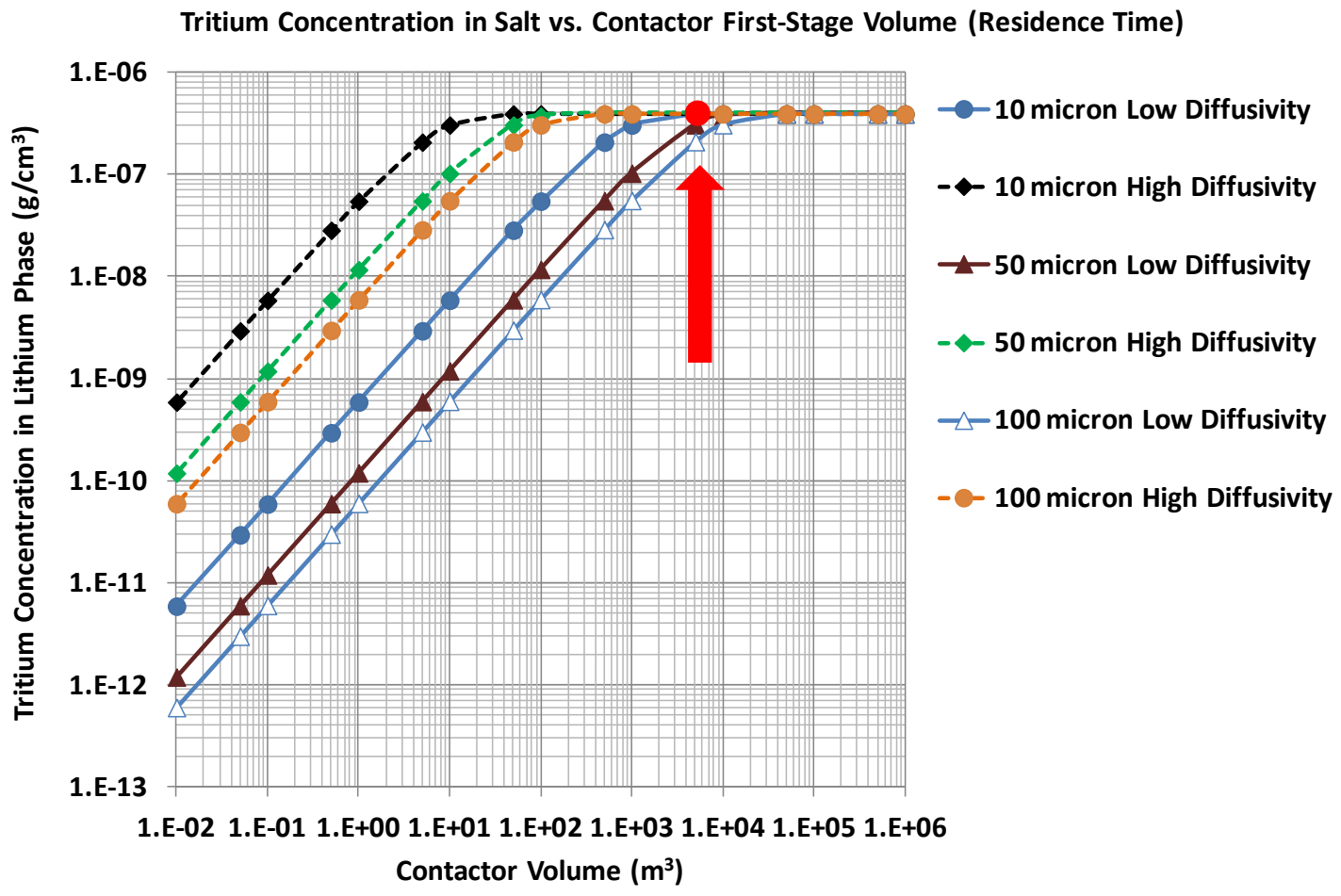

Figure 16 - This figure shows the the calculated tritium concentration in molten salt phase for the simple vertical extraction column of the type shown in Figure 14. 


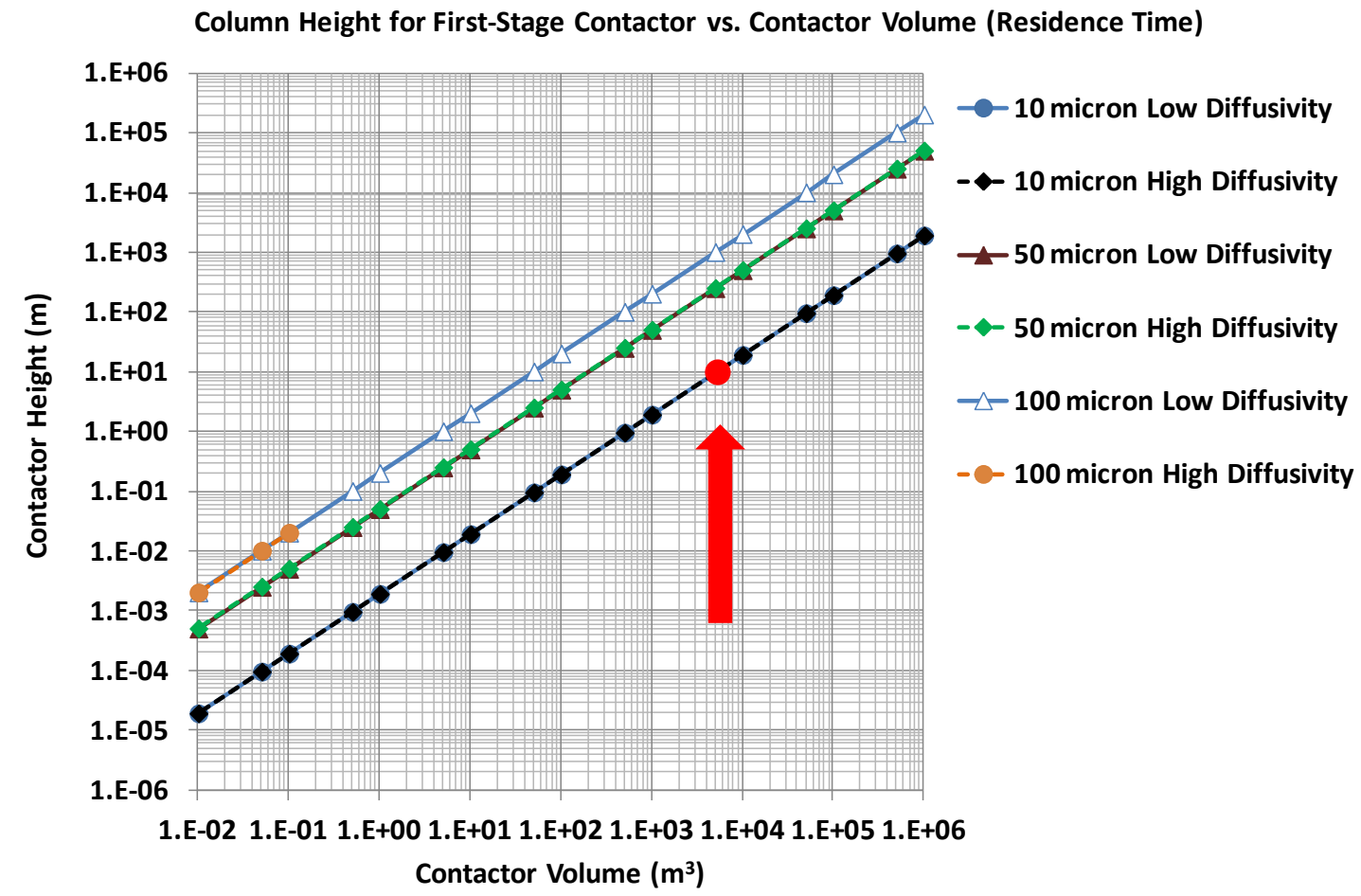

Figure 17 - This figure shows the corresponding total (combined) column heights for vertical extraction column of the type shown in Figure 14.

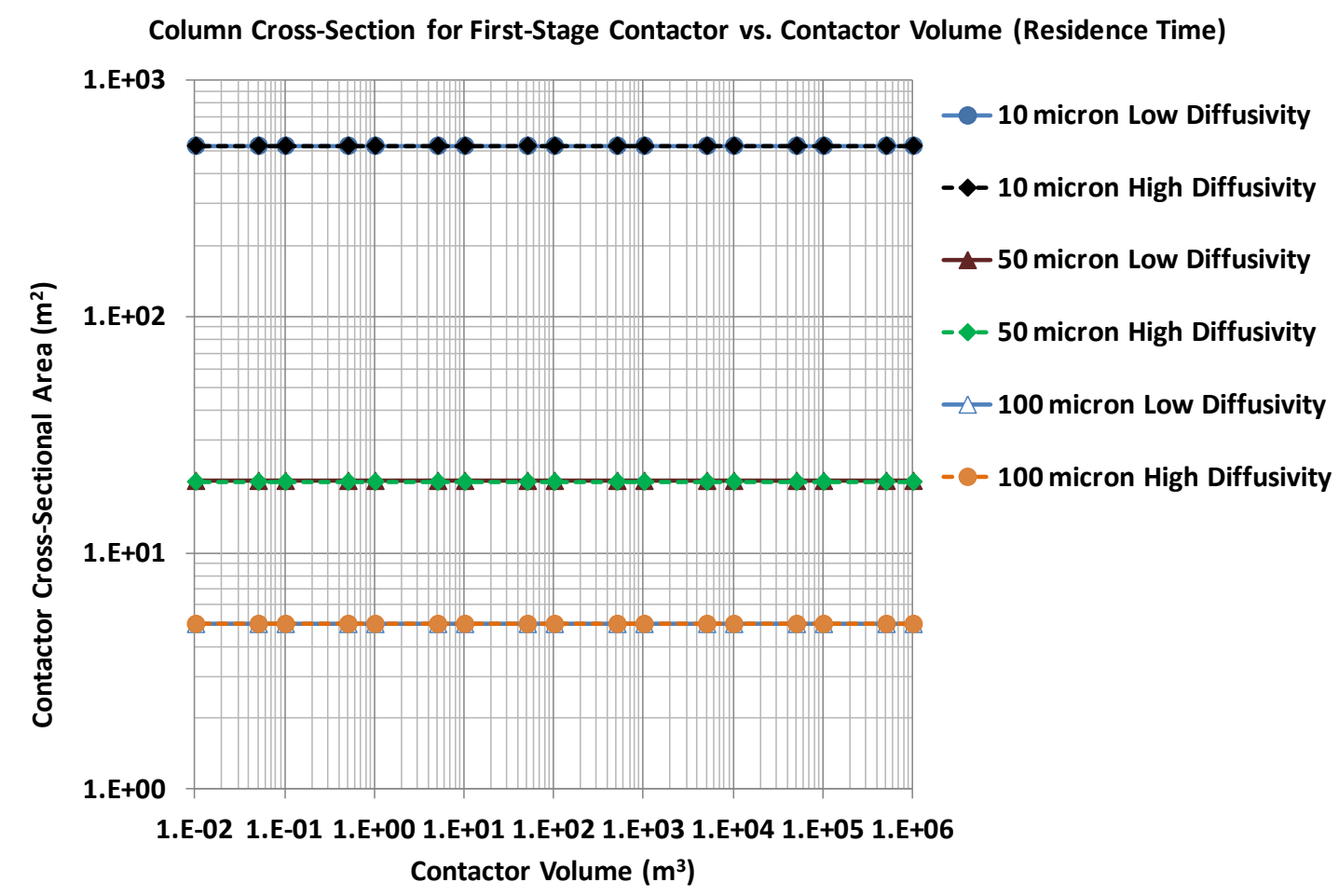

Figure 18 - Corresponding total (combined) column volumes for vertical extraction column of the type shown in Figure 16. 


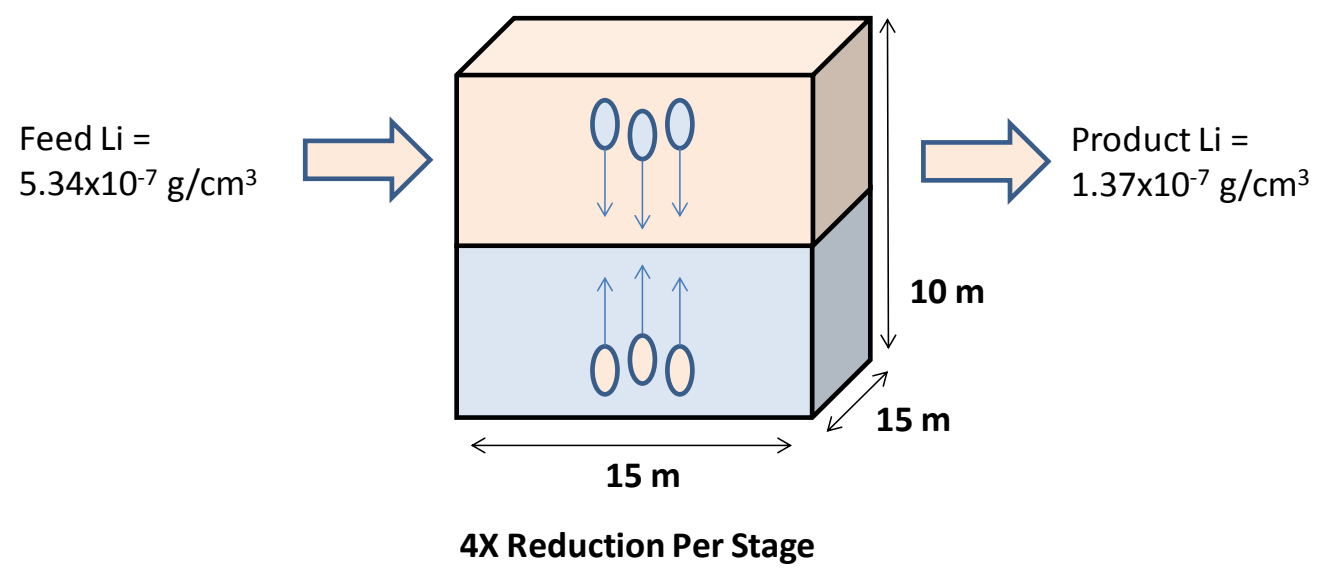

Figure 19 - Vertical extraction column with no optimization $(10 \mathrm{~m} \times 15 \mathrm{~m} \times 15 \mathrm{~m})$. As a baseline, the performance possible with a simple non-centrifugal gravity-driven system with droplets created by 10, 50 and 100 micron distributor plates has been investigated. Assuming conservative values of diffusivity, such a system is found to be relatively large during preliminary analysis.

C. Methods for Reducing the Size of Non-Centrifugal Contactors: Various means exist for decreasing the size of the contactors, without having to resort to the problematic rotating machinery involved in conventional centrifugal contactors:

1. In addition to maximizing interfacial surface area between the two flowing phases by utilizing distributer plates with holes suspended in the flow, employ (a) pulsed flow; (b) ultrasonic emulsification; (c) bi-stable flapping hydrofoil surfaces in the flowing stream; and/or (d) electromagnetically-pulsed droplet movement.

2. Continue to provide adequate residence time for inter-phase mass transfer by designing the flow system with sufficient volume.

3. Use induced turbulence to increase the inter-phase mass transfer coefficient between the lithium and salt phases by (a) increasing the linear velocity in flow channels; (b) incorporate fixed turbulence promoters in the flow channel, including radial, vertical, and/or horizontal vanes and blades; (c) employ high levels of agitation with tuned-frequency ultrasonic stimulation, coupling the acoustic transmitter to the high-temperature flow channel with a ceramic, glass, refractory metal, or appropriate amorphous metal coupler, thereby enabling the acoustic energy to be transmitted into the high temperature environment from the source, without exposing the source to the high-temperature environment.

4. Consolidation and separation of the liquid lithium and molten salt phases through the use of (a) flow pulsations causing collision and contact between droplets of variable size and drag force; (b) cyclonic action during flow; and (c) ultrasonic agglomeration to decrease the surface to volume ratio of the distributed phase.

Figure 20 shows a device with enhanced mass transfer and extraction efficiency through the use of fixed and/or spinning axial turbulence promoters in cylindrical or rectangular flow channel. Figure 21 shows a device with enhanced mass transfer and extraction efficiency through the use of bi-stable hydrofoil type turbulence promoters in cylindrical or rectangular flow channel. Figure 22 shows a device with enhanced mass transfer and extraction efficiency through the use of acoustic emulsification and mass transfer enhancement in cylindrical or rectangular flow channel. Figure 23 shows a device with phase separation with flow-induced cyclonic action. 


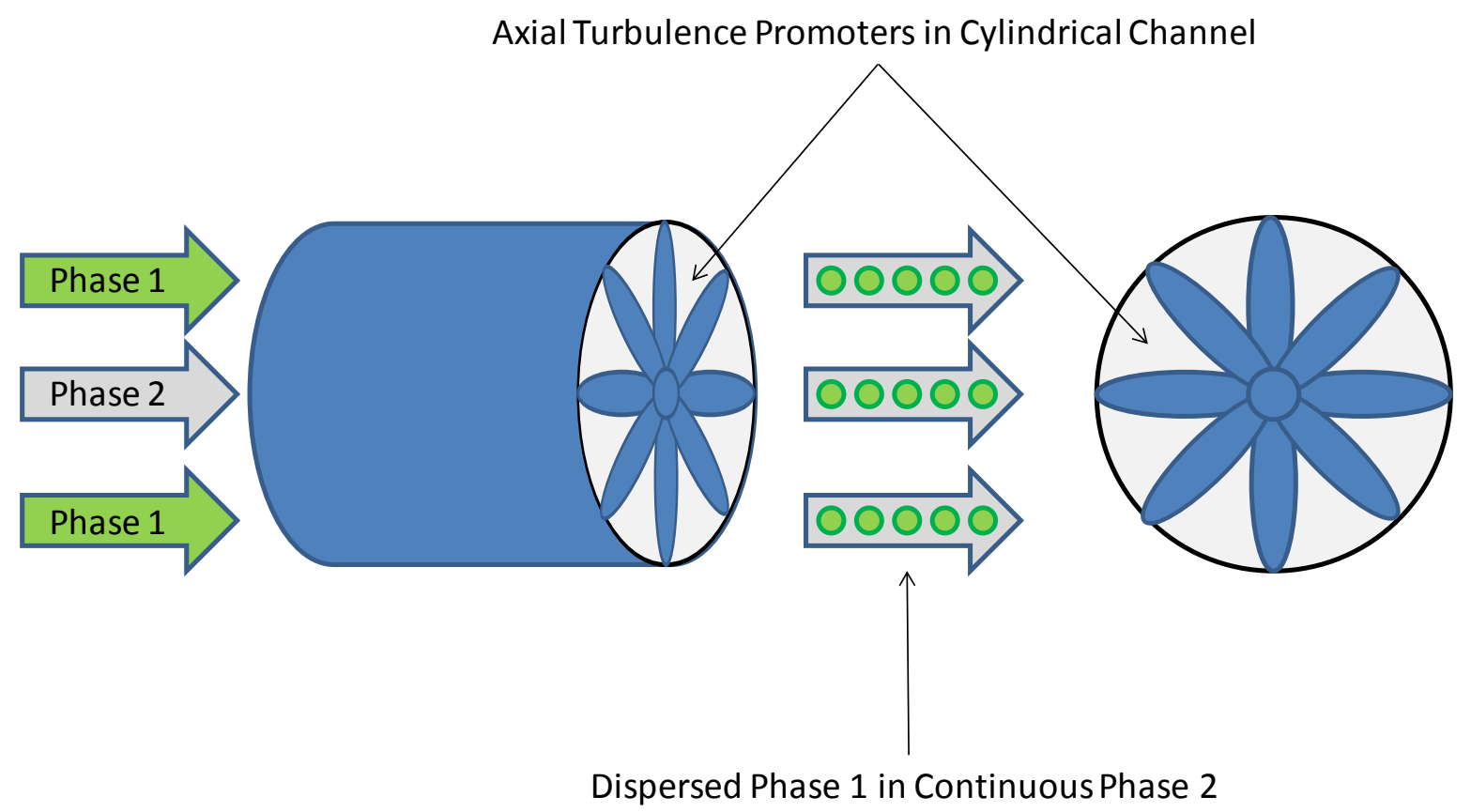

Figure 20 - Enhanced mass transfer and extraction efficiency through the use of fixed and/or spinning axial turbulence promoters in cylindrical or rectangular flow channel.

Flow-Driven Oscillating Bi-Stable Turbulence Promoters in Cylindrical Channel

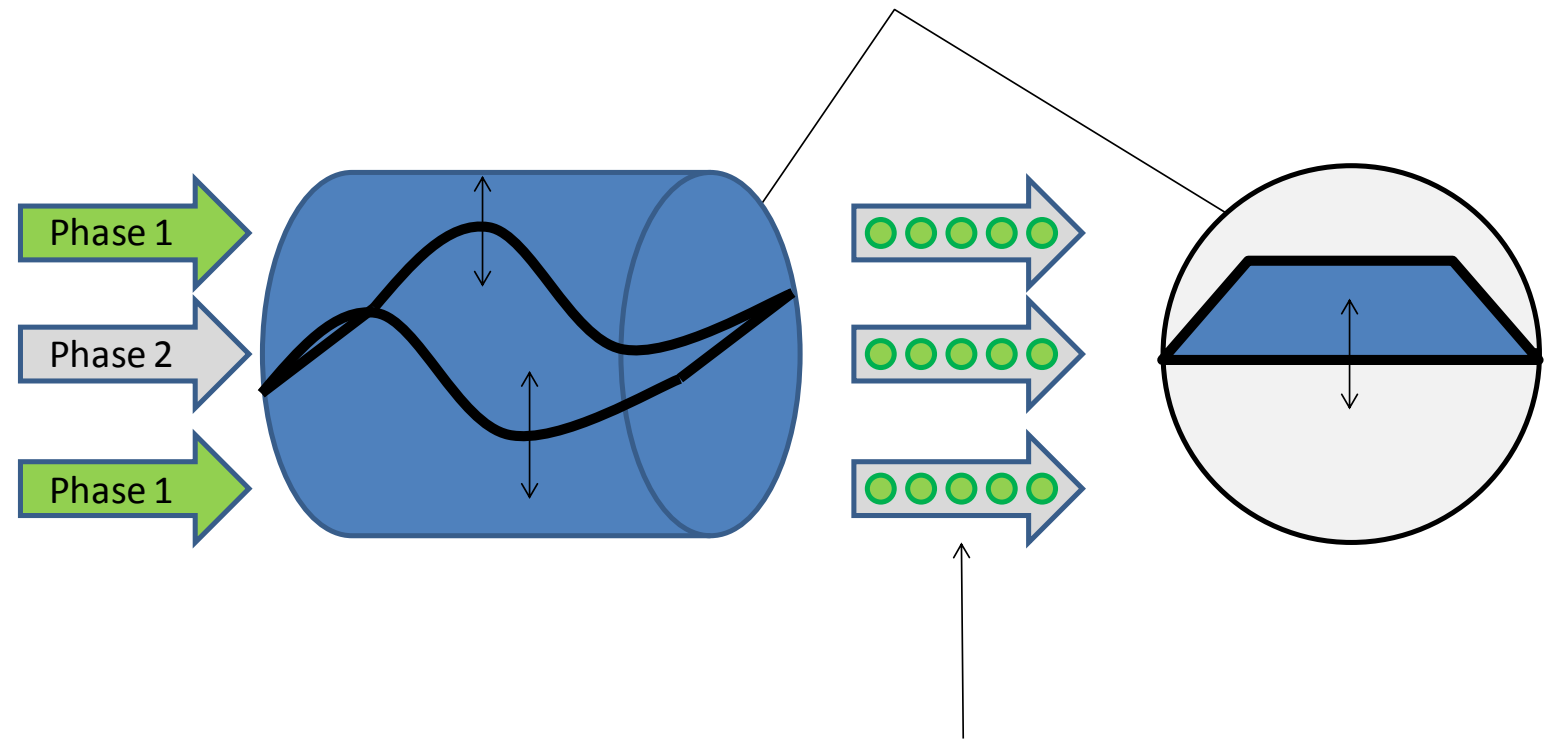

Dispersed Phase 1 in Continuous Phase 2

Figure 21 - Enhanced mass transfer and extraction efficiency through the use of bi-stable hydrofoil type turbulence promoters in cylindrical or rectangular flow channel. 


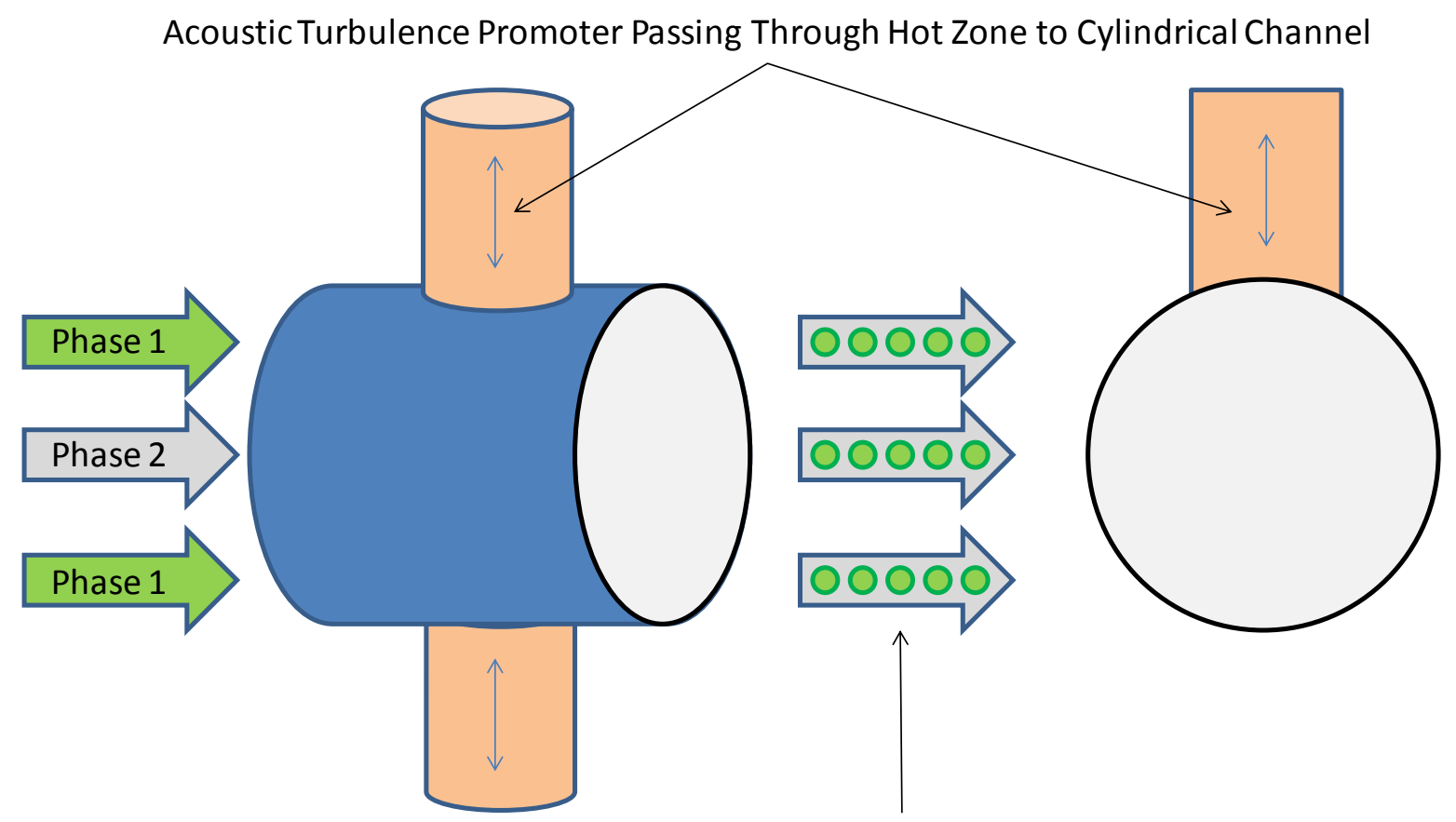

Dispersed Phase 1 in Continuous Phase 2

Figure 22 - Enhanced mass transfer and extraction efficiency through the use of acoustic emulsification and mass transfer enhancement in cylindrical or rectangular flow channel.

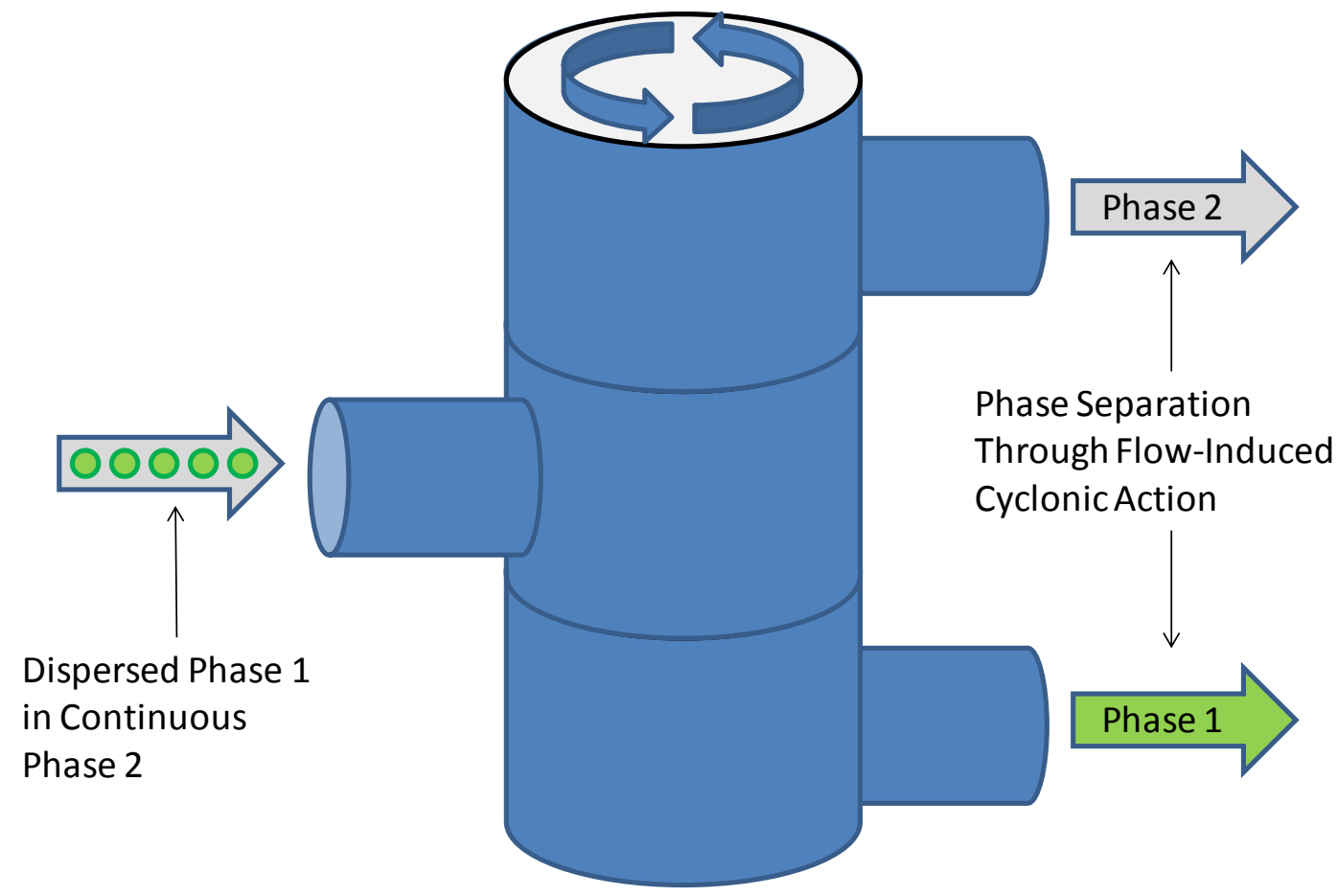

Figure 23 - Phase separation with flow-induced cyclonic action. 


\section{Experimental Development}

LLNL scientists and engineers are uniquely qualified to study and assess the potential of these hightemperature electrochemically-based separation processes, based upon several decades experience with industrial-scale electrochemistry in a nuclear environment, and the operation of state-of-the-art electrochemical instrumentation with electrolytic cells operating at 900 to $1000^{\circ} \mathrm{C}$.

The high-temperature electrochemical cell at LLNL that is being used to prove the electrochemistry necessary for the halide-free alternative to Maroni tritium separation process is shown in Figure 24. The furnace and glove box capability shown in the above figure are being used to demonstrate the separation of molten lithium hydroxide and metallic lithium phases, as shown here. This is an essential step in the identification of alternatives to the lithium fluoride system. The furnace and glove box capability shown Figure 24 are being used to demonstrate the separation of molten lithium hydroxide and metallic lithium phases, as shown in Figure 25. This is an essential step in the identification of alternatives to the lithium fluoride system.

The viability of using a hydro-cyclone for the separation of immiscible liquid phases has been demonstrated with both CFD models using COMSOL, as well as with clear plastic models like the one shown in Figure 26. In this case, oil and water are separated in the hydro-cyclone (clear section of pipe on the right). An oil-water mixture is injected tangentially into the middle of the clear pipe, via a white polyvinyl chloride (PVC) pipe fitting. This tangential injection induces cyclonic motion inside the clear section of pipe, with the lighter oil phase rising, and the heavier water phase falling. This working model, or an improved version, will be used to generate data for the validation and calibration of CFD models of the hydro-cyclone. Once developed, these models will then be used to design a high-temperature hydrocyclone for the separation of molten lithium salts from molten metallic lithium. 

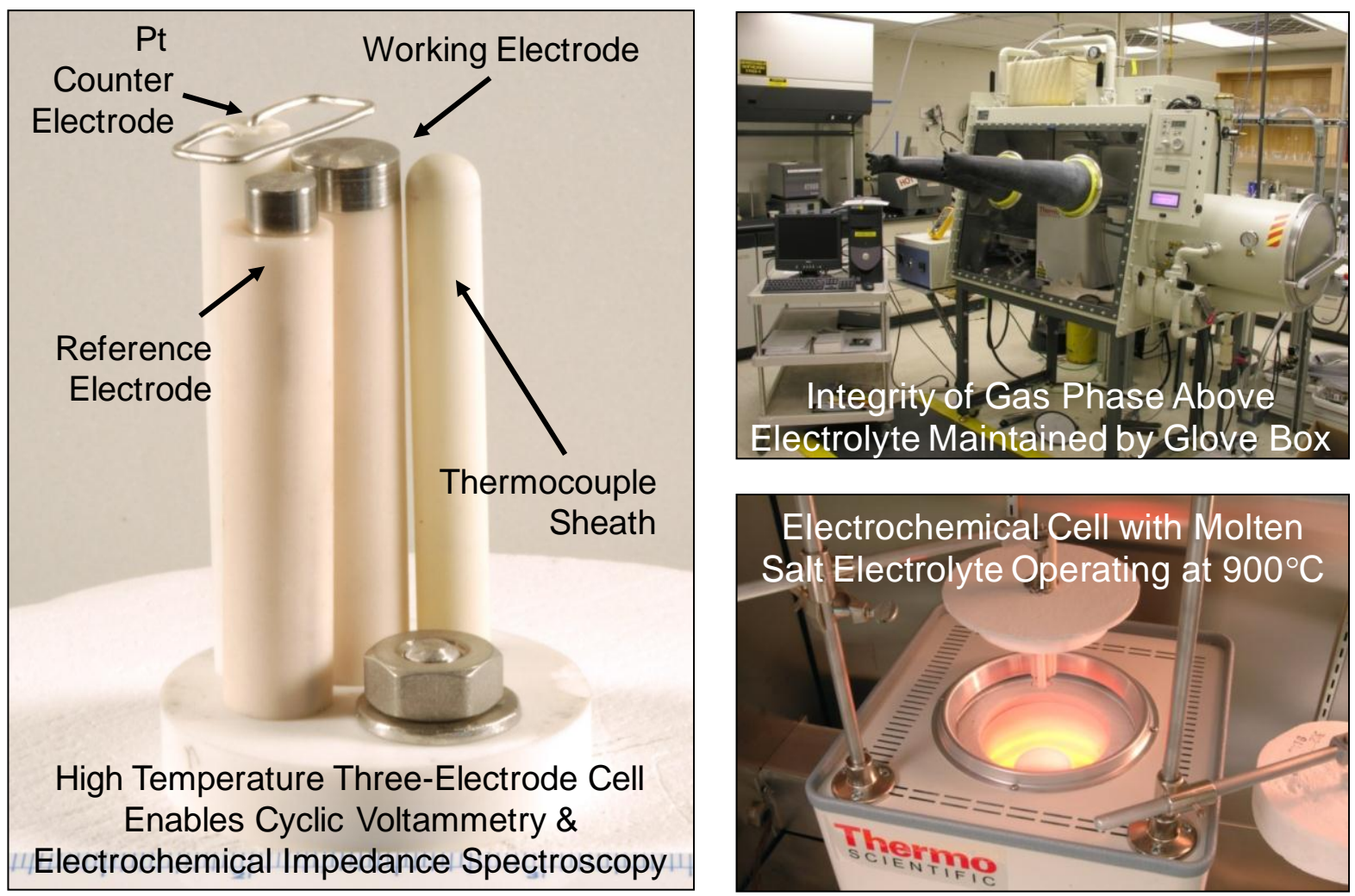

Figure 24 - High-temperature electrochemical cell at LLNL for proving the electrochemistry necessary for the halide-free alternative to Maroni tritium separation process, initially developed for hightemperature in-situ electrochemical studies of corrosion of LIFE chamber materials during exposure to high-temperature molten fluoride salts such as FLiBe and FLiNaK.
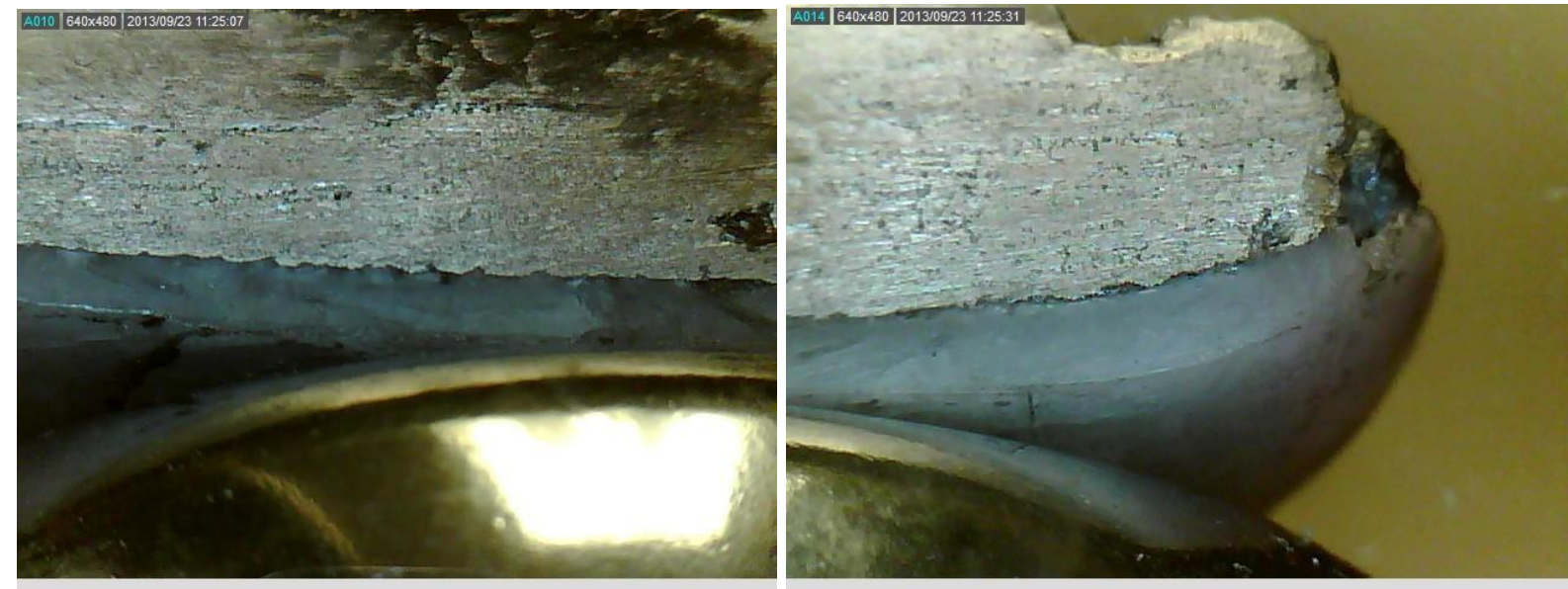

Figure 25 - The furnace and glove box capability shown in the above figure are being used to demonstrate the separation of molten lithium hydroxide and metallic lithium phases, as shown here. This is an essential step in the identification of alternatives to the lithium fluoride system. 

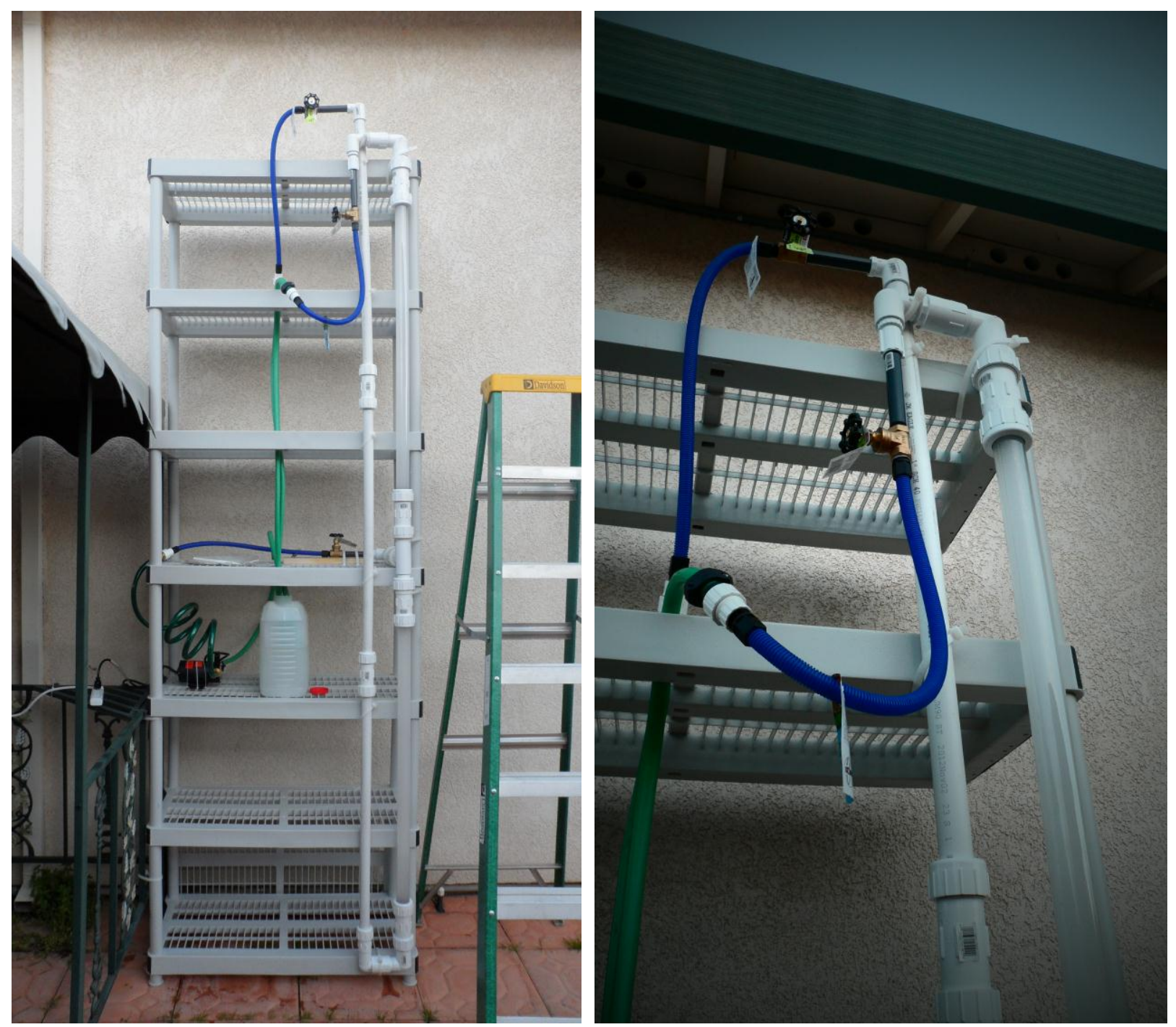

Figure 26 - The viability of using a hydro-cyclone for the separation of immiscible liquid phases has been demonstrated with both CFD models using COMSOL, as well as clear plastic models, as shown here. In this case, oil and water are separated in the hydro-cyclone (clear section of pipe on the right). 


\section{Summary}

LLNL's strategic thrust in Laser Inertial Fusion Energy (LIFE) is pursuing a laser-driven inertial confinement fusion power plant, to provide an alternative source of clean nuclear energy with none of the waste disposal or proliferation drawbacks associated with conventional fission reactors. LIFE requires tritium fuel be continuously removed from the blanket so that it can be returned to the reactor for burning, via target manufacturing in the case of LIFE. The baseline process for accomplishing this in the LIFE reactor is the well-known Maroni process which uses high-temperature molten mixed alkali-metal halide salts ( $\mathrm{LiCl}: \mathrm{LiF}: \mathrm{LiBr}$ at $530^{\circ} \mathrm{C}$ ) as an extraction solvent. The volatility of tritium fluoride and other such chemical species complicate this separation. An alternative electrolytic process for the conversion of lithium tritide to tritium gas and metallic lithium is based upon the use of a benign lithium hydroxide $(\mathrm{LiOH})$ or lithium carbonate $\left(\mathrm{Li}_{2} \mathrm{CO}_{3}\right)$ electrolyte, which is an extremely attractive alternative to the very volatile and corrosive lithium halide electrolyte. The separation of the molten lithium and molten chloride salt phases requires numerous high-temperature $\left(530^{\circ} \mathrm{C}\right)$ high-speed centrifugal separators, with bearings and seals exposed to the highly corrosive fluids. These high-speed centrifugal contactors must operate at high temperature for prolonged periods of time without failure. Such rotating machinery, with a highly corrosive molten salt electrolyte, and a liquid lithium phase threatening liquid metal embrittlement is a source of substantial concern. The proposed work will lead to less problematic and more reliable tritium recovery technology for LIFE, enhancing the viability of the overall concept.

Fusion reactors now on the drawing table, including LLNL's LIFE reactor, require liquid lithium blankets for cooling and breeding tritium fuel. The tritium fuel must be continuously removed from the blanket so that it can be returned to the reactor for burning, via target manufacturing in the case of LIFE. The baseline process for accomplishing this in the LIFE reactor is the well-known Maroni process which uses high-temperature molten mixed alkali-metal halide salts ( $\mathrm{LiCl}: \mathrm{LiF}: \mathrm{LiBr}$ at $530^{\circ} \mathrm{C}$ ) as an extraction solvent. With the generation of hydrogen isotopes, liquid and gaseous acids such as $\mathrm{HCl}, \mathrm{HF}$ and $\mathrm{HBr}$ (and the deuterium and tritium analogs) form in the salt phase, making these solvents very corrosive, with other problems due to volatility. Following extraction of lithium tritide from the molten lithium, the tritide anion must undergo electrochemical oxidation in a high-temperature electrochemical cell to form tritium gas, which can then be separated by stripping in a stream of inert gas such as xenon or helium. The volatility of hydrogen chloride or the tritium analog $(\mathrm{HCl}$ or $\mathrm{TCl})$, hydrogen fluoride or the tritium analog ( $\mathrm{HF}$ or TF) and hydrogen bromide or the tritium analog ( $\mathrm{HBr}$ or $\mathrm{TBr}$ ) complicate this separation. An alternative electrolytic process for the conversion of lithium tritide to tritium gas and metallic lithium is based upon the use of a benign lithium hydroxide $(\mathrm{LiOH})$ or lithium carbonate $\left(\mathrm{Li}_{2} \mathrm{CO}_{3}\right)$ electrolyte, which is an extremely attractive alternative to the very volatile and corrosive lithium halide electrolyte.

The separation of the molten lithium and molten chloride salt phases will require numerous hightemperature $\left(530^{\circ} \mathrm{C}\right)$ high-speed centrifugal separators, with bearings and seals exposed to the highly corrosive fluids. Currently, centrifugal contactors are used to contact the liquid lithium in which the tritium is bred with a molten salt extraction solvent. These high-speed centrifugal contactors must operate at high temperature for prolonged periods of time without failure. Such rotating machinery, with a highly corrosive molten salt electrolyte, and a liquid lithium phase threatening liquid metal embrittlement is a source of substantial concern. The invention disclosed here is a non-centrifugal contactor capable of operating without any moving parts. 


\section{Acknowledgements}

This work was performed under the auspices of the U.S. Department of Energy by Lawrence Livermore National Laboratory under Contract DE-AC52-07NA27344.

\section{Disclaimer}

This document was prepared as an account of work sponsored by an agency of the United States government. Neither the United States government, nor Lawrence Livermore National Security LLC, nor any of their employees make any warranty, expressed or implied, or assumes any legal liability or responsibility for the accuracy, completeness, or usefulness of any information, apparatus, product, or process disclosed, or represents that its use would not infringe privately owned rights. Reference herein to any specific commercial product, process, or service by trade name, trademark, manufacturer, or otherwise does not necessarily constitute or imply its endorsement, recommendation, or favoring by the United States government or Lawrence Livermore National Security, LLC. The views and opinions of authors expressed herein do not necessarily state or reflect those of the United States government or Lawrence Livermore National Security, LLC, and shall not be used for advertising or product endorsement purposes. 


\section{References}

1. S. Vedantam and J. B. Joshi, Review Paper, Annular Centrifugal Contactors, A Review, July 2006, Transactions of the Institution of Chemical Engineering, Part A, Chemical Engineering Research and Design, 84 (A7), July 2006, 522-542.

2. J. C. Farmer, Electrochemical Treatment of Mixed and Hazardous Wastes, Environmental Oriented Electrochemistry, C. A. C. Sequeira, Ed., Elsevier Science Publishers B. V., Amsterdam, The Netherlands, Studies in Environmental Science, Series 59, pp. 565-598 (1994).

3. Yoshiyuki Asaoka, Hirotake Moriyama, Yasuhiko Ito, Equilibrium Distributions of Tritium in Liquid Lithium / Molten Salt Systems, Journal of Nuclear Materials, 179-181 (1991) 879-881.

4. Hirotake Moriyama, Yoshiyuki Asaoka, Yasuhiko Ito, Kinetics of Tritium Recovery from Liquid Lithium by Molten Salt Extraction, Fusion Technology, 19 (1991) 1046-1050.

5. D. K. Sze, P. A. Finn, J. Bartlit, S. Tanaka, T. Teral, M. Yamawaki, Combined Gettering and Molten Salt Process for Tritium Recovery from Lithium, Fusion Engineering and Design 8, 1989, 339-344.

6. W.F. Calaway, Electrochemical Extraction of Hydrogen from Molten LiF-LiCl-LiBr and Its Application to Liquid-Lithium Fusion Reactor Blanket Processing, Nuclear Technology, 39, June 1978, pp. 63-74.

7. T. K. Sherwood, R. L. Pigford, C. R. Wilke, Rates of Mass Transfer at Surfaces with Simple Geometry, Chapter 6, Mass Transfer, McGraw-Hill Book Company, San Francisco, California, 1975 $(1975,1952,1937)$ pp. 199-254.

8. Victor A. Maroni, Raymond D. Wolson, Gustav E. Staahl, Some Preliminary Considerations of a Molten-Salt Extraction Process to Remove Tritium from Liquid Lithium Fusion Reactor Blankets, ANL Report, First ANS Topical Meeting on the Technology of Controlled Nuclear Fusion, San Diego, California, April $16^{\text {th }}$ through $18^{\text {th }} 1974,11$ pages.

9. C. O. Bennett, J. E. Myers, Convective Mass-Transfer Coefficients, Chapter 31, Mass Transfer with Laminar Flow, Chapter 32, Mass Transfer with Turbulent Flow, Chapter 33, Some Design Equations for Convective Mass Transfer, Chapter 34, Momentum, Heat and Mass Transfer, $2^{\text {nd }}$ Edition, McGraw-Hill Book Company, San Francisco, California, 1974 (1974, 1962), pp. 511-533, 534-543, 544-560, 561-581.

10. Dai-Kai Sze, John R. Bartlit, Rodger C. Martin, Titan-I Tritium Systems, Exact Date Unknown, ANL Report, Pages 12-1 through 12-29. 